\title{
G $\alpha 12$ activation in podocytes leads to cumulative changes in glomerular collagen expression, proteinuria and glomerulosclerosis
}

llene Boucher ${ }^{1,2}$, Wanfeng $\mathrm{Yu}^{1,2}$, Sarah Beaudry ${ }^{2}$, Hideyuki Negoro ${ }^{2, *}$, Mei Tran ${ }^{1,2}$, Martin R Pollak ${ }^{1}$ Joel $M$ Henderson ${ }^{3}$ and Bradley M Denker ${ }^{1,2}$

Glomerulosclerosis is a common pathological finding that often progresses to renal failure. The mechanisms of chronic kidney disease progression are not well defined, but may include activation of numerous vasoactive and inflammatory pathways. We hypothesized that podocytes are susceptible to filtered plasma components, including hormones and growth factors that stimulate signaling pathways leading to glomerulosclerosis. $\mathrm{G} \alpha 12$ couples to numerous G-proteincoupled receptors (GPCRs) and regulates multiple epithelial responses, including proliferation, apoptosis, permeability and the actin cytoskeleton. Herein, we report that genetic activation of $G \alpha 12$ in podocytes leads to time-dependent increases in proteinuria and glomerulosclerosis. To mimic activation of $\mathrm{G} \alpha 12$ pathways, constitutively active $\mathrm{G} \alpha 12$ (QL) was conditionally expressed in podocytes using Nphs2-Cre and LacZ/floxed QL $\alpha 12$ transgenic mice. Some $\mathrm{QL} \alpha 12^{\mathrm{LacZ}+/ \mathrm{Cre}+}$ mice developed proteinuria at 4-6 months, and most were proteinuric by 12 months. Proteinuria increased with age, and by 12-14 months, many demonstrated glomerulosclerosis with ultrastructural changes, including foot process fusion and both mesangial and subendothelial deposits. QL $\alpha 12^{\mathrm{LaCZ}+/ \mathrm{Cre}+}$ mice showed no changes in podocyte number, apoptosis, proliferation or Rho/Src activation. Real-time PCR revealed no significant changes in Nphs1, Nphs2, Cd2ap or Trpc6 expression, but Col4a2 message was increased in younger and older mice, while Col4a5 was decreased in older mice. Confocal microscopy revealed disordered collagen IV $\alpha 1 / 2$ staining in older mice and loss of $\alpha 5$ without changes in other collagen IV subunits. Taken together, these studies suggest that G $\alpha 12$ activation promotes glomerular injury without podocyte depletion through a novel mechanism regulating collagen $(\alpha)$ IV expression, and supports the notion that glomerular damage may accrue through persistent GPCR activation in podocytes.

Laboratory Investigation (2012) 92, 662-675; doi:10.1038/labinvest.2011.198; published online 16 January 2012

KEYWORDS: kidney; G proteins; G-protein-coupled receptors; signaling; chronic kidney disease; glomerulus

Glomerulosclerosis (GS) is a common pathological finding in patients with progressive chronic kidney disease (CKD) and often leads to end-stage renal disease. Numerous conditions predispose patients to GS, including diabetes, hypertension, IgA nephropathy, FSGS (focal segmental GS) and immunemediated injury. In adults over 60 years old, the prevalence of CKD Stage III (glomerular filtration rate, $30-59 \mathrm{ml} / \mathrm{min}$ ) is estimated to be $>25 \% .{ }^{1}$ Although risk factors such as hypertension and diabetes are linked to CKD, little is known about the signaling mechanisms that lead to progression with aging. Post-mortem and nephrectomy samples in otherwise 'healthy' adults reveal variable amounts of GS and interstitial fibrosis, suggestive of age-associated damage. ${ }^{2,3}$ Recent studies show that primary podocyte injury is sufficient to induce GS. ${ }^{4,5}$ Podocytes are exposed to filtered reactive oxygen species (ROS), lipid mediators, cytokines and hormones that could contribute to injury. Many of these molecules activate G-protein-coupled receptors (GPCRs), which couple to multiple $G \alpha$ subunits. Each of the $16 \mathrm{G} \alpha$ subunits (four main families: $\mathrm{G} \alpha \mathrm{s}, \mathrm{G} \alpha \mathrm{i} / \mathrm{o}, \mathrm{G} \alpha \mathrm{q}$ and $\mathrm{G} \alpha 12 / 13$ ) couples to many different GPCRs; ${ }^{6}$ thus, defining specific pathways in vivo has been difficult.

$\mathrm{G} \alpha 12 / 13$ are expressed in podocytes and couple to angiotensin II, thrombin, endothelin and LPA receptors, which are

\footnotetext{
${ }^{1}$ Renal Division, Beth Israel Deaconess Medical Center, Boston, MA, USA; ${ }^{2}$ Renal Division, Brigham and Women's Hospital, and Harvard Medical School, Boston, MA, USA and ${ }^{3}$ Department of Pathology and Laboratory Medicine, Boston University School of Medicine, Boston, MA, USA

Correspondence: BM Denker, MD, Renal Division, Beth Israel Deaconess Medical Center, 330 Brookline Avenue, Boston, MA 02215, USA.

E-mail: bdenker@bidmc.harvard.edu

*Current Address: University of Tokyo, Tokyo Medical and Dental University, Tokyo, Japan.

Received 2 July 2011; revised 18 October 2011; accepted 20 November 2011
} 
important in renal injury. ${ }^{7}$ G $\alpha 12 / 13$ can activate Rho or Src to regulate the actin cytoskeleton, ${ }^{8}$ in addition to proliferation, transformation, ${ }^{9}$ tight junction assembly, ${ }^{10-12}$ cell-cell adhesion, ${ }^{13,14}$ directed cell migration, ${ }^{15}$ apoptosis ${ }^{16}$ and cell attachment. ${ }^{17}$ RhoGDI $\alpha$ knockout mice develop proteinuria and renal failure, ${ }^{18}$ and many mutations in hereditary FSGS affect proteins linked to the actin cytoskeleton (reviewed in ref. 19). G $\alpha 12$ also upregulates $\operatorname{TGF} \beta,^{20,21}$ and several gene profiling studies found upregulated $\mathrm{G} \alpha 12$ in proteinuric kidneys and post-transplant CKD (via Nephromine ${ }^{22,23}$ ).

Targeting activated $G \alpha$ subunits to specific cells in vivo permits identification of downstream effector pathways independent of receptor activation, and thus permits insight into disease mechanisms otherwise impossible to study in vivo. Herein, we confirm the expression of endogenous $\mathrm{G} \alpha 12$ in the major podocyte processes. Constitutively activated $\mathrm{G} \alpha 12(\mathrm{QL} \alpha 12)$ was expressed in podocytes using a transgenic model that results in mosaic expression and mimics the focal nature of GS pathology. QL $\alpha 12^{\mathrm{LacZ}+/ \mathrm{Cre}+}$ mice develop proteinuria and focal GS without differences in podocyte number, apoptosis, proliferation or Rho/Src signaling over time. Col4a was dysregulated and correlated with altered localization and ultrastructural changes. These findings indicate that $G \alpha 12$ activation in podocytes leads to dysregulated collagen $\alpha(\mathrm{IV})$ expression and support a model of altered glomerular structure and function resulting from time-dependent stimulation of GPCR-G $\alpha 12$ signaling pathways.

\section{MATERIALS AND METHODS Transgenic Mice Creation}

All animal procedures were performed in accordance with the guidelines of the Institutional Animal Care and Use Committee at Harvard University. G $\alpha 12$ (Q229L) EE tagged was cloned into the CMV-floxed LacZ cassette kindly provided by Dr Larry Holzman. ${ }^{24}$ C57/B6 mice were injected at the Brigham and Women's Hospital Transgenic Mouse Facility and were then crossed with Nphs2/Cre mice on the same C57/BL6 background.

\section{Urine Microalbumin, Serum Creatinine, LPS and Tissue Harvesting}

Male and female mice were analyzed for urine microalbumin/ creatinine ratio at specified ages using Bayer DCA $200+$ Analyzer with software version E3.11/01.04. Mice were defined as proteinuric when microalbumin/creatinine ratio was $\geq 34$ owing to the detection limits of the analyzer. LPS (Invivogen, San Diego, CA, USA) (10 $\mu \mathrm{g} / \mathrm{g}$, intraperitoneally) was administered to 2- to 6-month-old mice, and urine was collected $18 \mathrm{~h}$ post-injection and microalbumin/creatinine ratio was determined. Serum was collected and BUN and creatinine were analyzed using an iStat System with CHEM8 + cartridges. Mice were anesthetized using inhaled isofluorane (Phoenix Pharmaceuticals, St Louis, MO, USA). For whole kidney collection, organs were perfused with cold
PBS. Kidneys were removed and processed according to methods below.

\section{GST-TPR Pull-Down Assay}

The GST-TPR construct was kindly provided by Dr M Negishi (Kyoto University, Kyoto, Japan). GST-TPR was prepared as described previously. ${ }^{16}$ Harvested kidneys were homogenized in lysis buffer with eComplete (Roche, Indianapolis, IN, USA) protease inhibitors, lysed through $22 \mathrm{G}$ needle and normalized for protein concentration. GSTTPR $(1 \mu \mathrm{g})$ coupled to glutathione-agarose beads (Amersham Biosciences) was added to $800 \mu \mathrm{g}$ of total protein and rocked overnight at $4^{\circ} \mathrm{C}$. Beads were pelleted with low-speed centrifugation and washed three times with PBS, $0.1 \%$ Triton $\mathrm{X}-100$, resuspended in Laemmli sample buffer and analyzed by SDS-PAGE and western blot using a G $\alpha 12$ antibody (Santa Cruz, Santa Cruz, CA, USA).

\section{Immunogold Electron Microscopy}

Immunogold labeling and electron microscopy (EM) was performed at the Membrane Biology Program, Massachusetts General Hospital. Normal mouse kidney was fixed in $2 \%$ freshly made paraformaldehyde and $0.5 \%$ glutaraldehyde in $0.1 \mathrm{M}$ phosphate buffer ( $\mathrm{pH} 7.4$ ) and processed according to standard conditions. Grids were incubated with rabbit anti$\mathrm{G} \alpha 12$ (Santa Cruz) overnight at $4^{\circ} \mathrm{C}$, followed by a $25 \mu \mathrm{l}$ droplet of anti-goat IgG conjugated with gold $(10 \mathrm{~nm})$. Grids were washed and imaged using Philips CM10 electron microscope (Philips Electronics, Mahwah, NJ, USA).

\section{Histology}

Fixed kidney tissue was paraffin processed and $4 \mu \mathrm{m}$ sections were stained with PAS. Light microscopic evaluation included quantification of the total number of glomeruli present in one microscopic section as well as quantification of glomeruli with lesions (global sclerosis, segmental sclerosis, glomerular collapse and glomerular hypertrophy).

\section{Electron Microscopy}

Fixed specimens were trimmed, post-fixed with osmium tetroxide, dehydrated in serial ethanols and embedded in epoxy resin. Ultrathin sections were cut at $80 \mathrm{~nm}$, mounted on 200 mesh copper grids, treated with uranyl acetate and lead citrate, and examined in a JEOL 1010 transmission electron microscope (Tokyo, Japan). Electron micrographs showing glomerular ultrastructure were analyzed in a blinded manner. Podocytes, endothelium, glomerular basement membrane (GBM) and mesangium were examined and scored from 0 (no abnormality) to 4 (severe abnormality). Podocytes were scored for foot process (FP) effacement and irregularity, microvillous degeneration, vacuolization and subepithelial deposits. Endothelium was scored for: double contours, subendothelial deposits and swelling. GBM abnormalities were scored for thickness and irregularity, and the 
mesangium was scored for deposits, expansion by matrix and cellular expansion.

\section{LacZ, TUNEL and Immunostaining}

Fixed kidneys were washed in PBS and rehydrated overnight in $30 \%$ sucrose. Kidneys were embedded in OCT Compound (TissueTek, Sakura Finetek, Torrence, CA, USA) and frozen in liquid nitrogen. For Wilms's tumor-1 (WT-1) and TUNEL staining, sections were labeled using the 'In Situ Cell Death Detection Kit' (Roche) according to the manufacturer's protocol. Kidneys were incubated in methanol, blocked and incubated in anti-WT-1 antibody (sc-192; Santa Cruz) at $4^{\circ} \mathrm{C}$ overnight. Sections were washed, incubated with appropriate secondary antibody and mounted using Prolong Gold (Invitrogen, Carlsbad, CA, USA). Kidneys were photographed on a Nikon E-1000 equipped with a SPOT digital camera. For collagen staining, kidneys were blocked in $1 \%$ BSA and incubated with primary antibodies (generous gift of DB Borga, Vanderbilt, Nashville, TN, USA) or (Rockland Gilbertsville, PA, USA). All sections were incubated with appropriate secondary antibody for $1 \mathrm{~h}$ at room temperature, and mounted using Prolong Gold (Invitrogen). Images were taken on a Nikon C1 D-Eclipse confocal microscope.

\section{Glomerular Isolation}

Glomerular isolation was performed using magnetic beads. ${ }^{25}$ A measure of $200 \mu \mathrm{l}$ Dynabeads (M450 Tosylactivated; Invitrogen) were washed with $0.1 \%$ PBS and incubated overnight in $0.2 \mathrm{M}$ Tris ( $\mathrm{pH}$ 8.5) with $0.1 \%$ BSA. Beads were washed and resuspended in $30 \mathrm{ml}$ HBSS. Mice were anesthetized and organs perfused with HBSS. Kidneys were digested in $1 \mathrm{mg} / \mathrm{ml}$ collagenase A (Roche) and $100 \mathrm{U} / \mathrm{ml}$ DNaseI (New England Biolabs, Ipswich, MA, USA) at $37^{\circ} \mathrm{C}$ for $30 \mathrm{~min}$. Digests were strained though a $100 \mu \mathrm{m}$ cell strainer, centrifuged and resuspended in HBSS. Glomeruli were obtained using magnetic separator (New England Bio Labs).

\section{RhoA Activation ELISA and Western Blot}

Isolated glomeruli were resuspended in lysis buffer with eComplete (Roche) protease inhibitors and lysed through $22 \mathrm{G}$ needle. Rho activity was determined using G-LISA ${ }^{\mathrm{TM}}$ RhoA Activation Assay Kit (Cytoskeleton, Denver, CO, USA) and absorbance at $490 \mathrm{~nm}$ of an HRP-active RhoA antibody. In addition, samples were analyzed by SDS-PAGE and western blot analysis using an anti-RhoA antibody (Cytoskeleton) as described previously. ${ }^{17}$

\section{Real-Time PCR}

Purified glomeruli were lysed in TRIzol reagent (Invitrogen). RNA concentrations were determined, and RNA was incubated in DNAseI (New England Biolabs) with RNAse inhibitor (Roche). DNAse-treated RNA was reverse transcribed using Transcriptor Reverse Transcriptase (Roche). Negative control without enzyme was included in each analysis.
The cDNA template was treated with RNaseH (Invitrogen). TaqMan Gene Expression assays (Applied Biosystems, Foster City, CA, USA) were performed using an ABI 7300 (Applied Biosystems) with the following conditions: $2 \mathrm{~min}$ at $50^{\circ} \mathrm{C}$ and $10 \mathrm{~min}$ at $95^{\circ} \mathrm{C}$, followed by 50 cycles of $95^{\circ} \mathrm{C}$ for $15 \mathrm{~s}$ and $60^{\circ} \mathrm{C}$ for $1 \mathrm{~min}$. Melting-curve analysis and gel electrophoresis of PCR products verified that a single product of the expected size was generated with each primer set. Data analysis used the $\Delta \Delta \mathrm{Ct}$ method. Ct was normalized to $18 \mathrm{~S}$ ribosomal subunit.

\section{Statistical Analyses}

Data are expressed as medians or means \pm s.e.m. as indicated. Statistical analysis was performed using Prism 4 for Macintosh (GraphPad, La Jolla, CA, USA) using two-way ANOVA, followed by Bonferroni's post-hoc test. Statistical significance was identified at $P<0.05$.

\section{RESULTS}

\section{$\mathbf{G} \alpha 12$ is Expressed in the Glomeruli}

Although $G \alpha 12$ is expressed in proximal and distal tubular epithelial cells ${ }^{26}$ and glomerular proteomics identified $\mathrm{G} \alpha 12,{ }^{27}$ its localization in the glomeruli has not been described. Endogenous $\mathrm{G} \alpha 12$ was localized in normal mouse glomeruli by immunohistochemistry. At lower power, $\mathrm{G} \alpha 12$ was detected in the glomeruli (Figure 1a, arrow heads) and throughout the nephron. At higher power (Figure 1a, black/ white arrows), several cell types, including podocytes, appear to express $\mathrm{G} \alpha 12$ with only background staining in the controls (antibody preincubated with peptide) (Figure 1a, b and d). To confirm podocyte G $\alpha 12$ localization, immunogold EM was performed (Figure 1b). Gold particles were visible in several locations, including FPs, major processes (MPs) and at the branch points proximal to the FPs (arrows). The localization of $G \alpha 12$ in MPs suggests that $G \alpha 12$ may have functions not directly related to slit diaphragm permeability.

\section{Establishing Transgenic Mice with Podocyte Expression of Activated $\mathrm{G} \alpha 12$ (QL $\alpha 12)$}

Mice expressing EE-tagged, human G $\alpha 12$ (Q229L) were established using a LacZ/floxed transgenic approach ${ }^{24}$ (Figure 2a). For conditional expression, ${ }^{28} \mathrm{QL} \alpha 12^{\mathrm{LacZ}+/ \text { Cre- }}$ mice were crossed with Nphs2-Cre mice (Nphs2 is efficiently expressed in podocytes and no other glomerular cells). ${ }^{29}$ Cre-mediated excision of the LacZ/stop in podocytes resulted in $\mathrm{QL} \alpha 12$ expression $\left(\mathrm{QL} \alpha 12^{\mathrm{LacZ}+/ \mathrm{Cre}+}\right)$ (Figure 2). The CMV promoter is associated with the mosaic expression due to random inactivation, ${ }^{24}$ although Cre efficiently excises LacZ in these podocytes. QL $\alpha 12^{\mathrm{LacZ}+/ \mathrm{Cre}-}$ (Control) and QL $\alpha 12^{\mathrm{LacZ}+/ \mathrm{Cre}+}$ mice at 2 months of age (littermates) were stained for $\beta$-gal using standard techniques. $\beta$-Gal staining revealed that transgene expression was low in proximal tubules, but higher in the papilla (as reported, ${ }^{24}$ not shown). $\mathrm{QL} \alpha 12^{\mathrm{LacZ}+/ \mathrm{Cre}+}$ mice showed a major reduction in glomerular LacZ staining (Figure 2b) compared with Cre- controls. A semiquantitative analysis of $\beta$-gal staining 
a
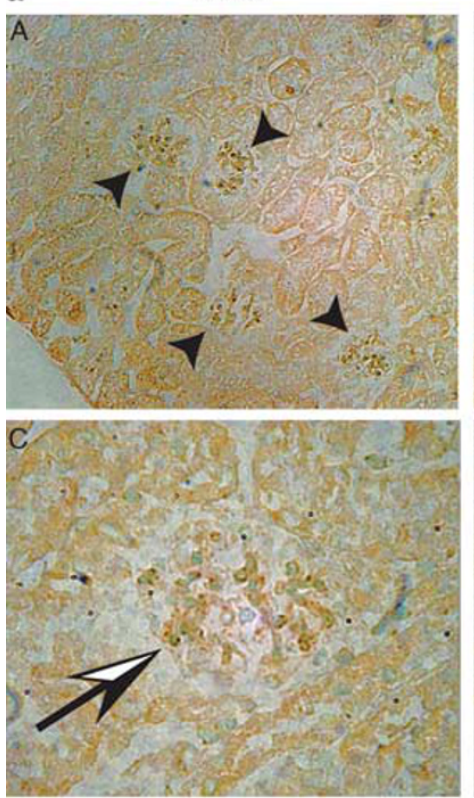

G $\alpha 12+\mathrm{Pep}$
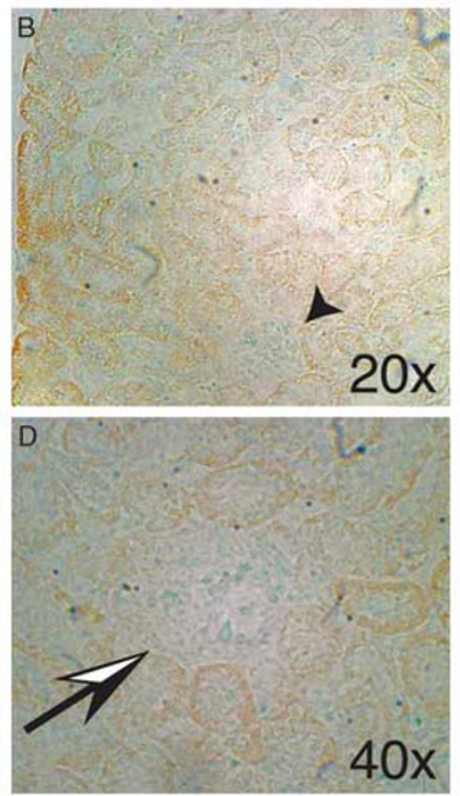

b

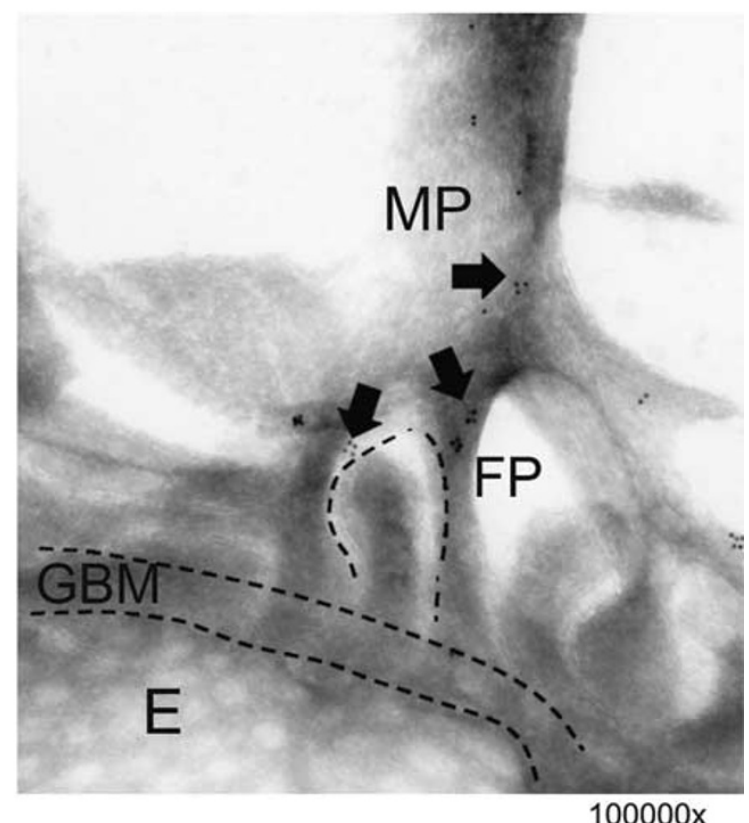

Figure 1 Endogenous $\mathrm{G} \alpha 12$ is expressed in normal mouse kidney. (a) Immunohistochemistry of normal mouse kidney demonstrates G $\alpha 12$ expression in glomeruli. Sections were probed with rabbit anti-G $\alpha 12$ and visualized with Vectastain. Two magnifications $(\times 20$ and $\times 40)$ are shown (panels A and B) Negative controls were performed by pre-incubating the antibody with excess blocking peptide (G $\alpha 12+$ Pep). Kidney sections using the blocked $G \alpha 12$ antibody showed a significant reduction in staining (panels B and D). (b) Immunoelectron microscopy shows that G $\alpha 12$ localizes to interdigitating foot processes (FP) and major processes (MP). Immunogold labeling and electron microscopy were performed as described in Materials and Methods. Magnification, $\times \sim 100000$. Arrows denote gold particles. Glomerular basement membrane (GBM), FP, fenestrated endothelium (E) and larger major processes (MP) are labeled.

suggested that random inactivation of the CMV promoter in podocytes led to LacZ expression in approximately half of the targeted cells (Supplementary Figure 1). Note that all the Cre + mice showed significantly less or no $\beta$-gal staining, while the controls were evenly distributed (Supplementary Figure 1). The small amount of residual LacZ staining in $\mathrm{QL} \alpha 12^{\mathrm{LacZ}+/ \mathrm{Cre}+}$ mice likely reflects $\mathrm{LacZ}$ expression in mesangial or endothelial cells. To distinguish EE-QL $\alpha 12$ expression from endogenous $\mathrm{G} \alpha 12$, control and $\mathrm{QL} \alpha 12^{\mathrm{LacZ}+/ \text { Cre }+}$ kidneys were co-stained with anti-nephrin and anti-EE antibodies (Figure 2c). In control mice, nephrin was seen throughout the glomerulus, with no detectable EE staining (Figure $2 \mathrm{c}$ and a). In QL $\alpha 12^{\mathrm{LacZ}+/ \mathrm{Cre}+}$ mice, both proteins were detected (Figure $2 \mathrm{c}$ and $\mathrm{b}$ ), and as expected from immunoEM (Figure 1b), there was little overlap with nephrin in the slit diaphragm. ImmunoEM using the EE epitope antibodies confirmed transgenic QL $\alpha 12$ expression (not shown) in a similar distribution to the endogenous $\mathrm{G} \alpha 12$ (Figure $1 \mathrm{~b}$ ). To confirm that active $\mathrm{G} \alpha 12$ was expressed in these glomeruli, GST-TPR pull downs were performed as described previously; ${ }^{16}$ the TPR domain of PP5 binds the active conformation of $\mathrm{G} \alpha 12 / 13 .{ }^{30}$ Figure $2 \mathrm{~d}$ shows GST-TPR pull downs of thrombin-stimulated MDCK cells compared with cortical kidney lysates from $\mathrm{QL} \alpha 12^{\mathrm{LacZ}+/ \mathrm{Cre}+}$ and $\mathrm{QL} \alpha 12^{\mathrm{LacZ}+/ \text { Cre- }}$ mice.

\section{QL 112 Expressed in Podocytes Leads to Age-Dependent Proteinuria}

Development of microalbuminuria is a sensitive marker for podocyte injury. ${ }^{31}$ Urine was analyzed for albumin/creatinine ratio (Figure 3a) from QL $\alpha 12^{\mathrm{LacZ}+/ \mathrm{Cre}+}$ and control mice every 2 months. Microalbuminuria (albumin/creatinine ratios $\geq 34$ ) appeared in a few control mice at 4-6 months, but was seen in $\sim 40 \%$ of $\mathrm{QL} \alpha 12^{\mathrm{LacZ}+/ \mathrm{Cre}+}$ mice (some with ratio $>200$; Figure 3 and Table 1). Most of the $\mathrm{QL} \alpha 12^{\mathrm{LacZ}+/ \mathrm{Cre}+}$ mice developed proteinuria as they aged, whereas only a few controls had mildly increased levels. Coomassie blue staining of urine confirmed the expression of albumin (Figure $3 \mathrm{~b}$ ). The magnitude of proteinuria continued to increase until mice were sacrificed at 22-26 months. On the basis of this phenotype, we divided the mice into young ( $<6$ months; occasional mild proteinuria) and older ( $>12$ months; frequent and often severe proteinuria) for further analysis.

The lack of proteinuria in most younger mice suggests that podocytes compensate for the expression of activated $\mathrm{G} \alpha 12$. To test whether QL $\alpha 12$ expression predisposed younger mice ( $<6$ months) to injury, proteinuria was examined after LPS stimulation (a model of transient podocyte injury) (Figure $3 \mathrm{c}$ ). ${ }^{32}$ Baseline proteinuria was similar, and $18 \mathrm{~h}$ after LPS stimulation, control mice increased proteinuria 1.9-fold, 
whereas $\mathrm{QL} \alpha 12^{\mathrm{LacZ}+/ \mathrm{Cre}+}$ mice showed a significantly larger increase (3.6-fold). However, these short-term experiments did not detect any differences in ultrastructural or light microscopy findings (not shown). These findings are consistent

a

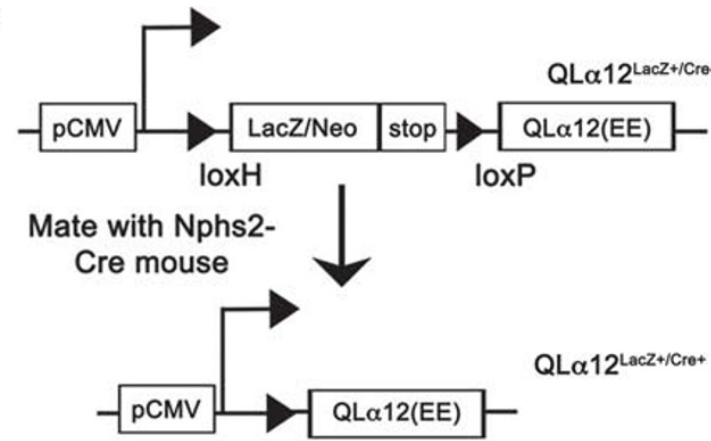

b
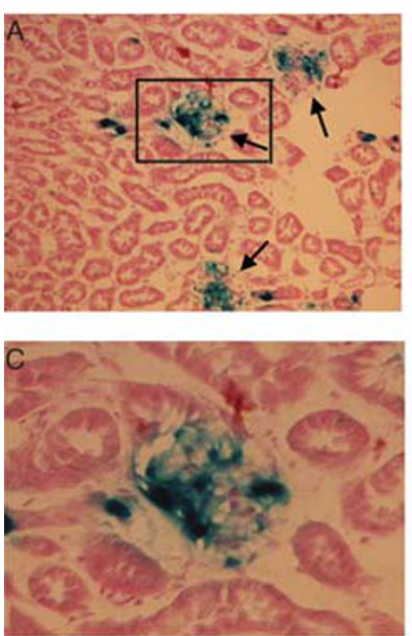

c

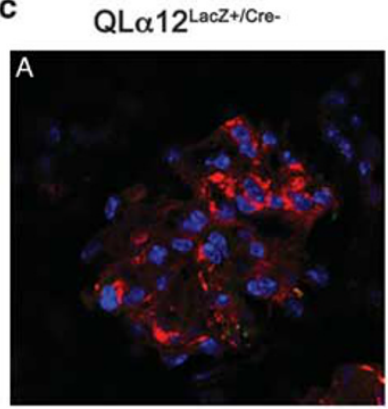

with LPS-stimulated podocyte actin cytoskeleton changes leading to proteinuria and reveal that podocyte expression of QL $\alpha 12$ in young mice enhances the injury response.

\section{Focal GS Develops with Age in QL $\alpha 12^{\text {LacZ }+/ \text { Cre }+}$ Mice}

In mice aged $<6$ months, no significant renal histopathological changes were observed in control or QL $\alpha 12^{\mathrm{LacZ}+/ \mathrm{Cre}+}$ mice (Figure $4 \mathrm{a}$ and e). However, by 12-18 months, $\mathrm{QL} \alpha 12^{\mathrm{LacZ}+/ \mathrm{Cre}+}$ mice showed numerous globally and segmentally sclerosed glomeruli, whereas controls exhibited only rare sclerosed glomeruli. Quantifying affected glomeruli showed a $>6$-fold increase in sclerosed glomeruli from kidneys of $\mathrm{QL} \alpha 12^{\mathrm{LacZ}+/ \mathrm{Cre}+}$ mice $(n=7)$ compared with controls $(n=7)$ (Figure $4 \mathrm{~b}$ and $\mathrm{f}$ ). Segmentally sclerosed glomeruli were characterized by hyalinosis, GBM reduplication, isolated epithelial cells containing PAS + protein reabsorption granules and adhesion of the tuft to Bowman's capsule. Mesangial areas of QL $\alpha 12^{\mathrm{LacZ}+/ \mathrm{Cre}+}$ mice exhibited mild to focally moderate expansion by matrix and cells, whereas the mesangial areas of control mice exhibited minimal expansion (Figure $4 \mathrm{~b}$ and $\mathrm{f}$, arrow). The kidneys of 18-month-old mice exhibited changes similar to the 12 - to 18 -month group, but more prominent. On average, $4.79 \%$ of glomeruli in QL $\alpha 12^{\mathrm{LacZ}+/ \mathrm{Cre}+}$ mice were globally or segmentally sclerosed, whereas only $0.16 \%$ of glomeruli in control mice were sclerosed (Figure $4 \mathrm{c}-\mathrm{e}$ and $\mathrm{h}$ ). Over $73 \%$ of these sclerosed glomeruli were juxtamedullary. Focal segmental double contours (areas of GBM redundancy) were more commonly seen in $\mathrm{QL} \alpha 12^{\mathrm{LacZ}+/ \mathrm{Cre}+}$ mice than in controls. Occasional PAS + hyaline casts were observed in the medulla to varying degrees in older animals as well as focal interstitial mononuclear inflammation, usually in association with focal GS (Figure $4 \mathrm{~g}$ and $\mathrm{h}$, arrows). Features of focal tubular injury, including tubular luminal distension, epithelial flattening and microcyst formation, were seen in a subset of the oldest QL $\alpha 12^{\mathrm{LacZ}+/ \mathrm{Cre}+}$ mice, and these findings were not seen in the age-matched controls. The nonlesional glomeruli (Figure 4h, arrowhead) exhibit moderate mesangial expansion by matrix and cells $\left(^{*}\right)$. Other features of active or chronic tubulointerstitial or vascular pathology

Figure 2 Development of transgenic mice with podocyte-specific expression of $\mathrm{QL} \alpha 12$. (a) Schematic of targeting epitope tagged (EE) human QL $\alpha 12$ to podocytes. The floxed LacZ/stop is driven by cytomegalovirus (CMV) promoter and Nphs-2 podocin-Cre was used for podocyte expression. (b) Transgenic mice show mosaic expression of LacZ. Control and QL $\alpha 12^{\mathrm{LacZ}+/ \mathrm{Cre}+}$ mice at 2 months of age (littermates) were stained for $\beta$-gal as describe in Materials and Methods. Insets (C and D) show an individual glomerulus. (c) $\mathrm{QL} \alpha 12^{\mathrm{LacZ}+/ \mathrm{Cre}+}$ mice express EE-tagged QL $\alpha 12$ in podocytes. Immunofluorescent staining was performed on control $(A)$ and $\mathrm{QL} \alpha 12^{\mathrm{LacZ}+/ \mathrm{Cre}+}$ (B) mice using fluorescein isothiocyanate (FITC)-conjugated goat anti-EE (shown in green) and guinea-pig anti-nephrin (Progen) and Cy3 secondary antibody (shown in red) (d) Activated $\mathrm{G} \alpha 12$ was pulled down from kidney lysates of QL $\alpha 12^{\mathrm{LacZ}+/ \mathrm{Cre}+}$ or thrombin-stimulated Madin-Darby canine kidney (MDCK) cells using GST-TPR or GST alone. 
were not observed in any animals. There were no detectable differences in serum creatinine between the 14- and 19month-old $\mathrm{QL} \alpha 12^{\mathrm{LacZ}+/ \mathrm{Cre}+}$ mice and controls as all values were $\leq 0.2 \mathrm{mg} / \mathrm{dl}$.

\section{Older Ql $\alpha 12^{\text {LacZ }+/ \text { Cre + }}$ Mice Develop GBM Irregularities, Mesangial Expansion and FP Fusion}

$\mathrm{EM}$ of $\mathrm{QL} \alpha 12^{\mathrm{LacZ}+/ \mathrm{Cre}+}$ and control mice $<6,12-18$ and $>18$ months were scored for ultrastructural abnormalities.
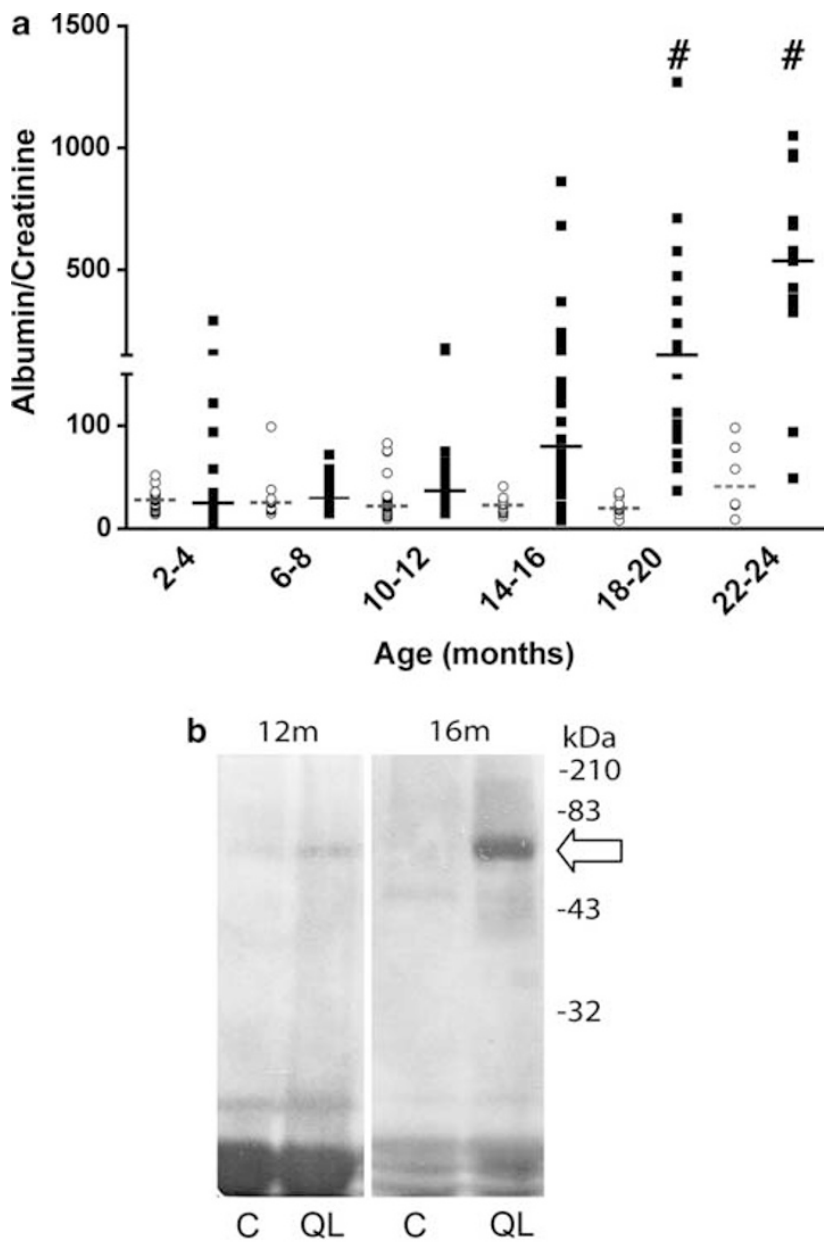

C

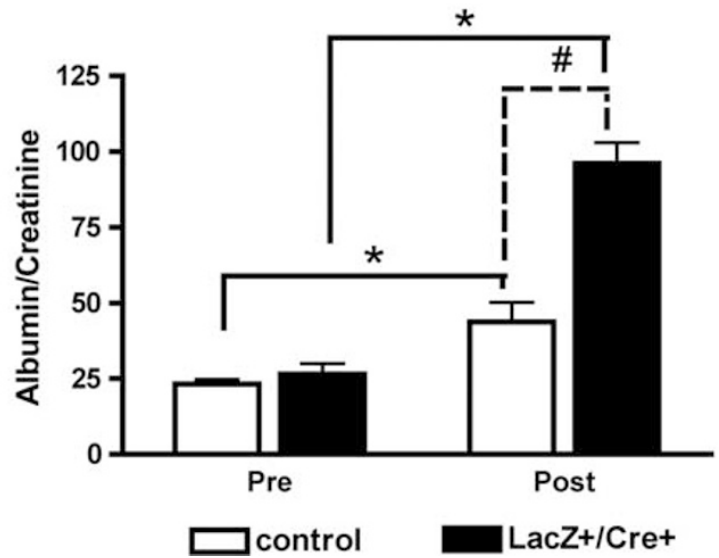

The youngest $\mathrm{QL} \alpha 12^{\mathrm{LacZ}+/ \mathrm{Cre}+}$ mice (Figure 5a) appeared normal. At 12-18 months, there was little difference in the GBM or the podocytes, but most QL $\alpha 12^{\mathrm{LacZ}+/ \mathrm{Cre}+}$ mice had focal features of endothelial injury, including double contours, subendothelial granular electron-dense deposits and cell swelling (Figure 5e, arrowhead; not seen in the controls). In addition, $\mathrm{QL} \alpha 12^{\mathrm{LacZ}+/ \mathrm{Cre}+}$ scored higher for mesangial expansion by matrix and cells (Figure $5 \mathrm{e}\left({ }^{*}\right)$; Table 2 ). Older $\mathrm{QL} \alpha 12^{\mathrm{LacZ}+/ \mathrm{Cre}+}$ mice (>18 months) (Figure 5f) mice exhibited a greater degree of FP effacement and irregularity, presumably associated with aging (Figure 5f, arrows) than was seen in the controls (although controls did reveal some age-related changes). There were few differences in the GBM, but there were an increased number of subepithelial GBM membrane projections in the oldest transgenics (Figure 5f, ४). All mice exhibited mild mesangial expansion at $>18$ months; however, QL $\alpha 12^{\mathrm{LacZ}+/ \mathrm{Cre}+}$ mice showed more severe signs of mesangial abnormalities (Figure $5 \mathrm{f},{ }^{*}$ ), and overall scores (Table 2) for glomerular injury were twice as high in the $\mathrm{QL} \alpha 12^{\mathrm{LacZ}+/ \mathrm{Cre}+}$ mice (Figure $5 \mathrm{c}$ ).

\section{QL $\alpha 12^{\text {LacZ }+/ \text { Cre }+}$ Mice have Normal Numbers of Podocytes}

On the basis of the morphological changes, we examined podocyte number by WT-1 staining. ${ }^{33}$ Surprisingly, podocyte number/glomerulus showed no difference between $\mathrm{QL} \alpha 12^{\mathrm{LacZ}+/ \mathrm{Cre}+}$ and controls $>12$ months (Figure 6a and b). As $\mathrm{G} \alpha 12$ can stimulate both proliferation and apoptosis, ${ }^{16}$ WT-1-positive cells were quantified for apoptosis (TUNEL) and proliferation (Ki67) to exclude the possibility that podocyte number was preserved through QL $\alpha 12$ co-stimulation of proliferation and apoptosis. No apoptotic podocytes were seen in $\mathrm{QL} \alpha 12^{\mathrm{LacZ}+/ \mathrm{Cre}+}$ or controls (Figure 6a, middle panels), nor any difference observed in proliferation (not shown). In addition, there were no differences in the number of glomeruli in kidneys obtained from $\mathrm{QL} \alpha 12^{\mathrm{LacZ}+/ \mathrm{Cre}+}$ mice as compared with controls

Figure $3 \mathrm{QL} \alpha 12^{\mathrm{LacZ}+/ \mathrm{Cre}+}$ mice develop of proteinuria with age. (a) Urine microalbumin/creatinine ratio in QL $\alpha 12$ mice is higher than in controls. Urine from control and QL $\alpha 12$ mice was monitored every 2 months using a BCA analyzer. Albumin/creatinine from individual control $(O)$ and $\mathrm{QL} \alpha 12(\boldsymbol{\square})$ mice are shown. Lines indicate median value (dashed, control; solid, QL $\alpha 12$ ). (b) Urine from QL $\alpha 12$ mice contains high levels of albumin. Urine from 12- and 16-month QL $\alpha 12$ (QL) and littermate control mice (c) was collected and analyzed by sodium dodecyl sulfate polyacrylamide gel electrophoresis (SDS-PAGE) and Coomassie blue staining. The arrow denotes $\sim 66 \mathrm{kDa}$, the size of excreted albumin. Note that the 12-month old mice had more concentrated urine (based on the nonspecific low-molecular-weight bands). (c) QL $\alpha 12$ mice are more susceptible to lipopolysaccharide (LPS)-induced injury. Control ( $n=17)$ and $\mathrm{QL} \alpha 12(n=21)$ mice were injected with $10 \mu \mathrm{g} / \mathrm{g}$ body weight of LPS. Urine was collected $18 \mathrm{~h}$ post-injection and analyzed for urine microalbumin/ creatinine ratio using a BCA analyzer. Statistical analysis was performed using two-way analysis of variance (ANOVA), followed by Bonferroni's post-hoc test $\left({ }^{\#} P<0.001 ;{ }^{*} P<0.0001\right)$. 
Table 1 Transgenic mice develop microalbuminuria

\begin{tabular}{|c|c|c|c|c|c|c|c|c|c|c|}
\hline \multirow{2}{*}{$\begin{array}{l}\text { Age (years) } \\
\text { Genotype }\end{array}$} & \multicolumn{2}{|c|}{$4-6$} & \multicolumn{2}{|c|}{$8-10$} & \multicolumn{2}{|c|}{$12-14$} & \multicolumn{2}{|c|}{$16-18$} & \multicolumn{2}{|c|}{$20-22$} \\
\hline & $\mathrm{C}$ & ++ & C & ++ & C & ++ & $\mathrm{C}$ & ++ & C & ++ \\
\hline \multicolumn{11}{|l|}{$A / C$} \\
\hline Average \pm s.e.m. & $28 \pm 1.7$ & $65 \pm 20$ & $32 \pm 5.5$ & $42 \pm 4.0$ & $26 \pm 2.4$ & $80 \pm 10$ & $20 \pm 1.3$ & $105 \pm 17^{*}$ & $29 \pm 8.1$ & $340 \pm 98^{x}$ \\
\hline
\end{tabular}

C, control mice; ++, QL $\alpha 12^{\text {LacZ+/Nphs2-Cre+ }}$ mice.

${ }^{*} P<0.001$, by two-way ANOVA, followed by Bonferroni's post-hoc test.
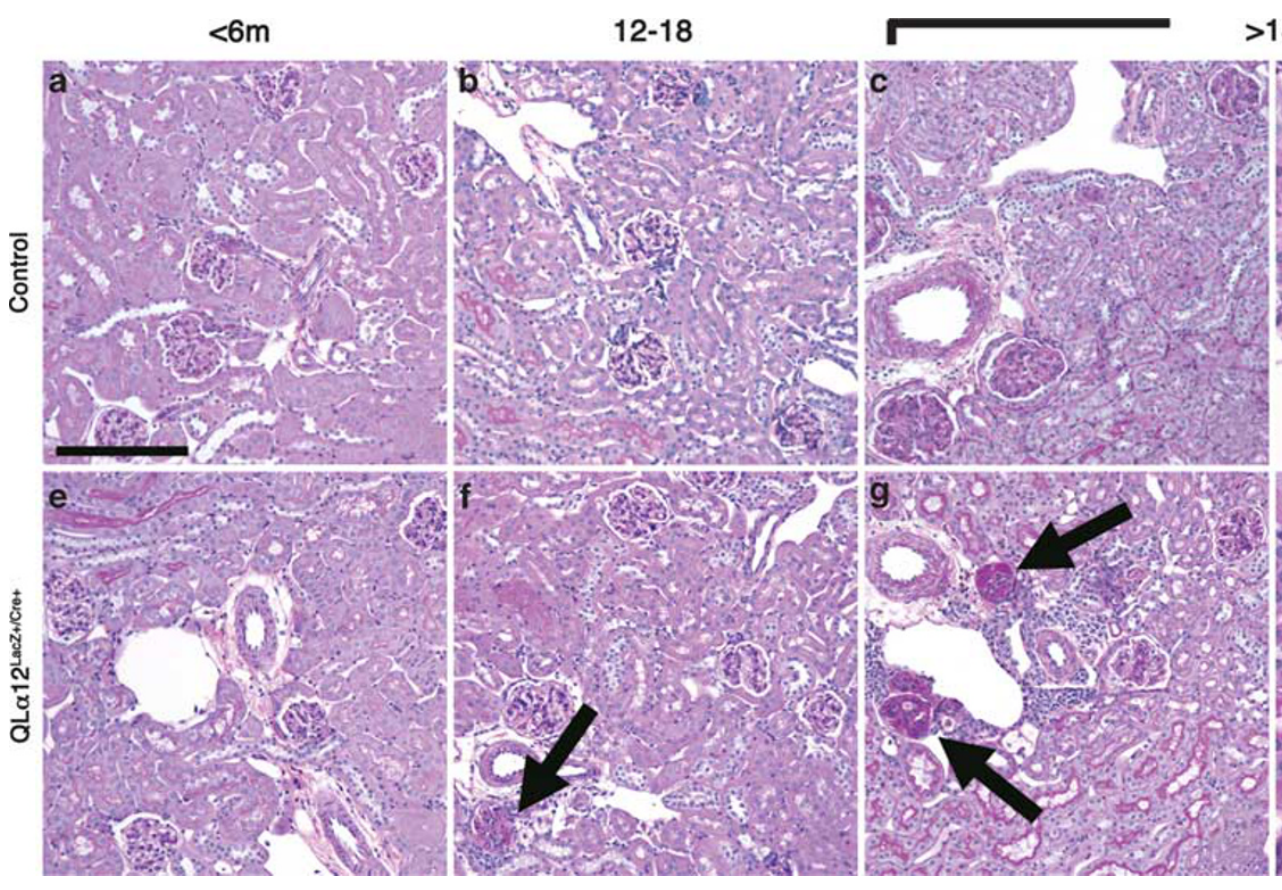

$>18$
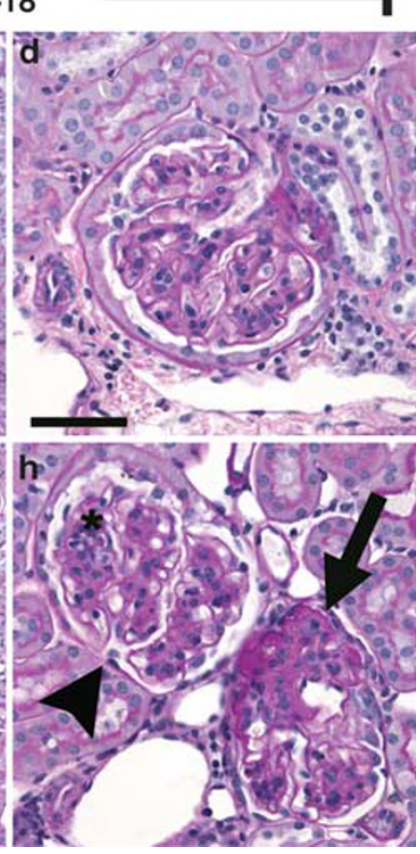

Figure 4 Light micrographs show focal and segmental glomerulosclerosis in the juxtamedullary region of older $\mathrm{QL} \alpha 12^{\mathrm{LacZ}+/ \mathrm{Cre}+}$ mice. Representative light micrographs of murine juxtamedullary kidney cortex in control (top row) and QL $\alpha 12^{\mathrm{LaCZ}+/ \text { Cre }+}$ (bottom row) mice aged $4.5,13$ and 24 months are shown. (a, e) Kidneys of mice aged $<6$ months, regardless of genotype, show no significant pathological changes in glomeruli, tubulointerstitium or vasculature. (b, f) Kidney of $\mathrm{QL} \alpha 12^{\mathrm{LacZ}+/ \mathrm{Cre}+}$ mice (f) aged 12-18 months exhibit focal glomerulosclerosis involving juxtamedullary glomerulus (arrow). The parenchyma is otherwise well preserved. Age-matched controls (b) show no significant pathological changes. (c, d, g, h) Kidneys of QL $\alpha 12^{\text {LacZ }+/ C r e+}$ mice aged $>18$ months show focal global $(\mathbf{g})$ and segmental (h) glomerulosclerosis involving multiple juxtamedullary glomeruli (arrows), accompanied by focal interstitial mononuclear inflammation. The non-lesional glomeruli ( $\mathbf{h}$; arrowhead) exhibit moderate mesangial expansion by matrix and cells $\left.{ }^{*}\right)$. Age-matched controls (c, d) show mild mesangial expansion, but no other cortical parenchymal lesions are apparent. PAS; bar $=100 \mu \mathrm{m}$ (left 3 columns) and $50 \mu \mathrm{m}$ (right column).

(data not shown). This indicates that the development of proteinuria and GS does not result from developmental effects on glomeruli number or podocyte depletion, and other mechanisms must be responsible.

\section{QL $\alpha 12$ Expression in Podocytes does not Lead to Rho or Src Activation}

Next, Rho activity was examined in QL $\alpha 12^{\mathrm{Lac}+/ \mathrm{Cre}+}$ and control mice. Rho activity was determined by ELISA on glomerular isolates from young and old mice. There were no significant differences in Rho activity from QL $\alpha 12^{\mathrm{Lac}+/ \mathrm{Cre}+}$ mice compared with controls, nor was there any difference in Rho protein expression (Figure $7 \mathrm{a}$ ). $\mathrm{G} \alpha 12$ also activates $\mathrm{Src},{ }^{34}$ and western blot using pY419 antibodies failed to demonstrate any differences in Src activation (not shown). This finding suggests that podocytes compensate for persistent QL $\alpha 12$ expression and employs other mechanisms to prevent sustained Rho or Src activation. 

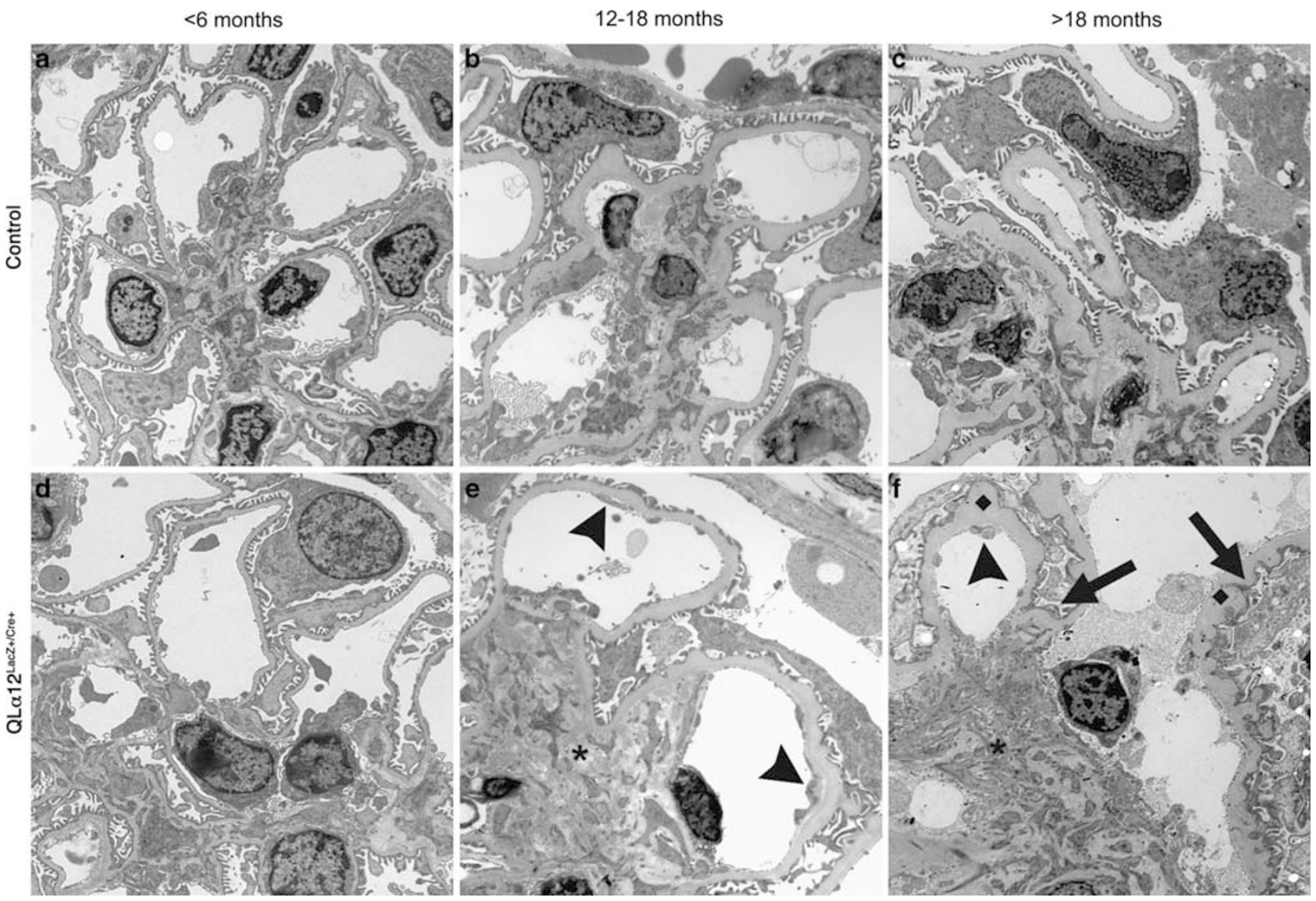

Figure $5 \mathrm{QL} \alpha 12^{\mathrm{LaCZ}+/ / \mathrm{Cre}+}$ develop foot process fusion and ultrastructural changes that worsen with age. Transmission electron microscopy (EM) was performed on kidneys from control and QL $\alpha 12^{\mathrm{LacZ}+/ \mathrm{Cre}+}$ mice at $<6(\mathbf{a}, \mathbf{d}), 12-18(\mathbf{b}, \mathbf{e})$ and $>18$ months $(\mathbf{c}$, f) were analyzed in a blinded manner and scored for severity of injury. Representative micrographs in control (top row) and QL $\alpha 12^{\mathrm{LacZ}+/ \text { Cre }+}$ (bottom row) mice aged 4,14 and 23 months are shown. At $<6$ months, both control (a) and QL $\alpha 12^{\mathrm{LacZ}+/ \mathrm{Cre}+}$ (d) show normal glomerular structure. By $12-18$ months, the QL $\alpha 12^{\mathrm{LacZ}+/ \mathrm{Cre}+}$ mice (e) show more signs of endothelial injury (arrowhead) and mesangial expansion $\left(^{*}\right)$ than controls $(\mathbf{b})$. All of the oldest mice examined show significant GBM thickening, but the QL $\alpha 12^{\mathrm{LacZ}+/ \text { /Cre }+}$ (f) show increased development of subepithelial basement membrane projections ( $)$ along the GBM. The podocytes have more foot process effacement and irregularity (arrow) in addition to the mesangial expansion $\left({ }^{*}\right.$ ) and endothelial injury (arrowhead) seen in the 12-18 months mice compared with controls (c).

\section{Real-Time PCR Showed no Changes in Podocyte-Specific Genes, but QL $\alpha 12^{\text {LacZ }+/ \text { Cre }+}$ Mice Exhibit Dysregulated Glomerular Collagen Expression}

Real-time PCR of glomerular isolates failed to detect changes in expression levels of several major podocyte genes implicated in FSGS (Nphs1, Nphs2, CD2AP and TRPC6) (Supplementary Figure 2). The normal adult GBM is composed predominantly of $\alpha 3, \alpha 4$ and $\alpha 5$ (IV) collagen and laminin-11 $(\alpha 5 \beta 2 \gamma 1){ }^{35}$ During development, the normal GBM is composed of $\alpha 1$ and $\alpha 2$ (IV) collagen that is followed by a switch to $\alpha 3, \alpha 4$ and $\alpha 5$ (IV) expression in mature glomeruli. Real-time PCR of Col4a showed increased Col4a2 transcript expression levels in younger mice (Figure 8a), although the variability in phenotype led to wide confidence intervals. These age-dependent changes are likely to contribute to the observed variability, and as this analysis was performed on isolated glomeruli, it is possible that the most severely sclerotic glomeruli were not included and would thus tend to underestimate the differences. In addition, the real-time results were reanalyzed in male and female mice, and no differences were observed to account for the differences in phenotype seen between transgenic and control mice in any age group (not shown). Nevertheless, when considered together, these results suggest a change in the relative balance of specific collagen $\alpha(\mathrm{IV})$ chains, and immunofluorescence microscopy confirmed mildly increased collagen $\alpha 1 / 2$ (IV) expression (Figure 8c). In older mice, Col4a2 expression abnormalities persist, and by $12-14$ months, there is also a twofold increase in Col4a1 and decreased Col4a5 (Figure 8c). Consistent with the real-time results, collagen $\alpha 1 / 2$ (IV) staining was increased in older mice, and the localization was disorganized without clear capillary loop staining (Figure 8d). Decreased expression of $\alpha 5$ was confirmed, although the pattern of staining appeared similar to the 
control (Figure 8d). No other $\alpha($ IV) chains showed differences in staining. The $\alpha 3 / 4 / 5$ antibody showed decreased intensity compared with the control, and based on the $\alpha 3$ staining and real-time results, this difference is most likely explained by the decreased $\alpha 5$ collagen expression. To determine if QL $\alpha 12$ directly regulates Col4 gene expression, a previously characterized inducible (tet off) QL $\alpha 12-\mathrm{MDCK}$ cell line ${ }^{10,11,17}$ was analyzed by microarray. Supplementary Figure 3 shows 7- and 10-fold increase in Col4a1 and Col4a2, respectively, within $72 \mathrm{~h}$ of QL $\alpha 12$ expression. Taken together, this analysis indicates that QL $\alpha 12$ expression leads to dysregulated Col4a gene expression before the onset of proteinuria and suggests a mechanism where activated $\mathrm{G} \alpha 12$ alters Col4 gene expression.

\section{DISCUSSION}

Understanding the mechanisms of CKD progression is important for finding new therapeutic targets. Podocytes are exposed to approximately 1801 of ultrafiltrate per day that contains biologically active molecules, including hormones, cytokines and filtered proteins. Herein, we demonstrate that activation of $\mathrm{G} \alpha 12$ in podocytes leads to age-dependent proteinuria and focal GS through a distinct mechanism involving dysregulated collagen $\alpha(\mathrm{IV})$ expression without podocyte depletion. This supports the hypothesis that filtered agonists activate podocyte signaling pathways and can contribute to progressive glomerular injury. Although $\mathrm{G} \alpha 12$ regulates numerous processes that could lead to podocyte damage, including apoptosis, proliferation, cell attachment, actin cytoskeletal changes and junctional regulation, these do not explain the time-dependent phenotype in these mice. Rather, a novel mechanism of collagen $\alpha$ (IV) abnormalities appears to be responsible.

Testing the notion that podocytes respond to filtered molecules is difficult to examine in vivo. Expressing a constitutively active $G$ protein allows for the identification of downstream effector pathways, and this approach led to the identification of h-Ras as an oncogene. ${ }^{36}$ This strategy could identify novel therapeutic targets to prevent GS without the

Table 2 QL $\alpha 12^{\text {LacZ+/Cre+ }}$ mice score higher for glomerular injury

\begin{tabular}{|c|c|c|c|c|c|c|c|c|c|c|}
\hline \multirow{2}{*}{$\begin{array}{l}\text { Injury } \\
\text { Genotype }\end{array}$} & \multicolumn{2}{|c|}{ FP EFF } & \multicolumn{2}{|c|}{ FP IRREG } & \multicolumn{2}{|c|}{ MicrovillL } & \multicolumn{2}{|c|}{ KNOBS } & \multicolumn{2}{|c|}{ DCs } \\
\hline & $\mathrm{C}$ & ++ & $\mathrm{C}$ & ++ & $\mathrm{C}$ & ++ & $\mathrm{C}$ & ++ & $\mathrm{C}$ & ++ \\
\hline \multicolumn{11}{|c|}{ Scores by age (months) } \\
\hline $12-18$ & 1 & 0.6 & 1.3 & 1 & 1 & 1 & 1.67 & 1.4 & 0.33 & 1 \\
\hline $18-24$ & 0 & 1.5 & 0.33 & 1.8 & 0.66 & 1.25 & 1 & 2 & 0 & 1.2 \\
\hline
\end{tabular}

Injury

Endothelium

\begin{tabular}{|c|c|c|c|c|c|c|c|c|}
\hline \multirow[b]{2}{*}{ Genotype } & \multicolumn{2}{|c|}{ Subend dep } & \multicolumn{2}{|c|}{ Swelling } & \multicolumn{2}{|c|}{ MES matrix } & \multicolumn{2}{|c|}{ MES cells } \\
\hline & $\mathrm{C}$ & ++ & C & ++ & $\mathrm{C}$ & ++ & $\mathrm{C}$ & ++ \\
\hline \multicolumn{9}{|c|}{ Scores by age (months) } \\
\hline$<12$ & 0 & 0 & 0 & 0.33 & 0.75 & 1 & 0.5 & 0.67 \\
\hline $12-18$ & 0 & 0.6 & 0 & 0.6 & 1 & 1.8 & 1 & 1.2 \\
\hline
\end{tabular}

C, control mice; ++, QL $\alpha 12^{\mathrm{LacZ}+/ \mathrm{Nphs} 2-\text { Cre+ }}$ mice; FP, foot process; EFF, effacement; IRREG, irregularity; DC, double contours; MES, mesangial.

Figure $6 \mathrm{QL} \alpha 12^{\mathrm{LacZ}+/ \text { Cre }+}$ mice have normal numbers of podocytes. (a) Wilms's tumor-1 (WT-1) staining shows little podocyte apoptosis in both control and QL $\alpha 12$ mice. In all, 24 fields and total $>200$ podocytes were counted for control and QL $\alpha 12^{\text {LacZ }+/ C r e+}$ mice. Terminal deoxynucleotidyl transferase dUTP nick end labeling (TUNEL) assays were performed on kidney sections from QL $\alpha 12$ and control mice 2-6 and 12-16 months of age. In addition, sections were probed for WT-1 and stained for 4',6-diamidino-2-phenylindole (DAPI). (b) WT-1 quantification shows similar number of podocytes in both control and QL $\alpha 12$ mice. The number of cells per glomeruli stained for both WT-1 and DAPI quantified for 100 glomeruli and averaged. 

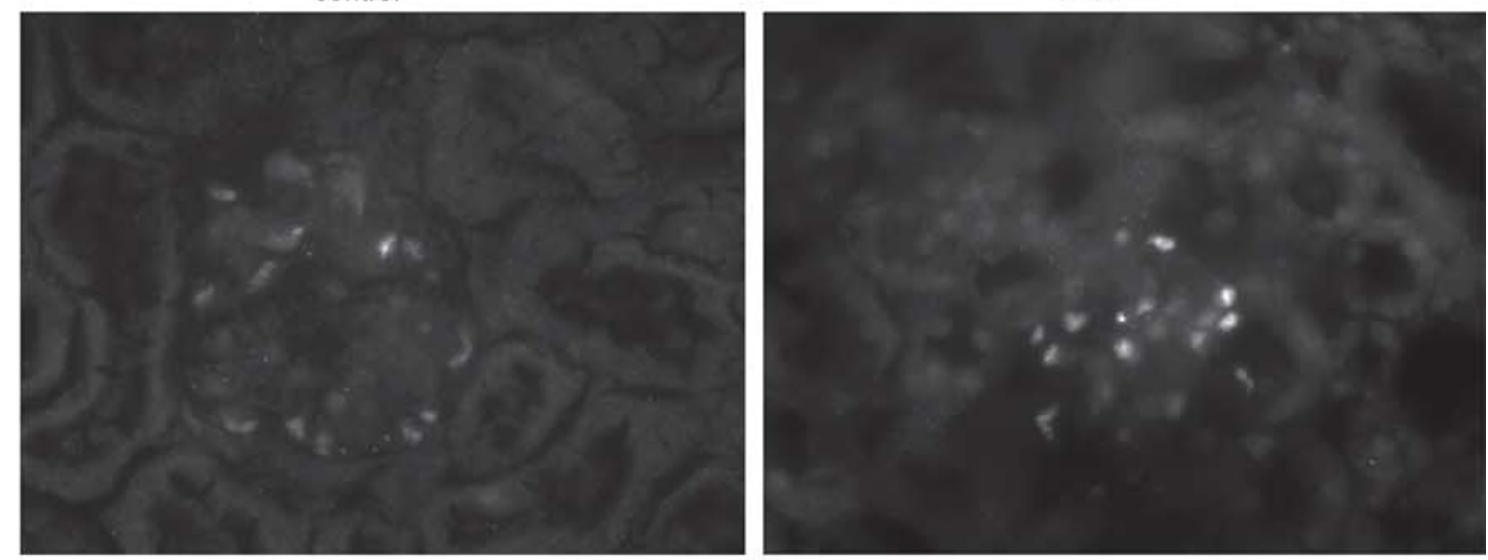

TUNEL
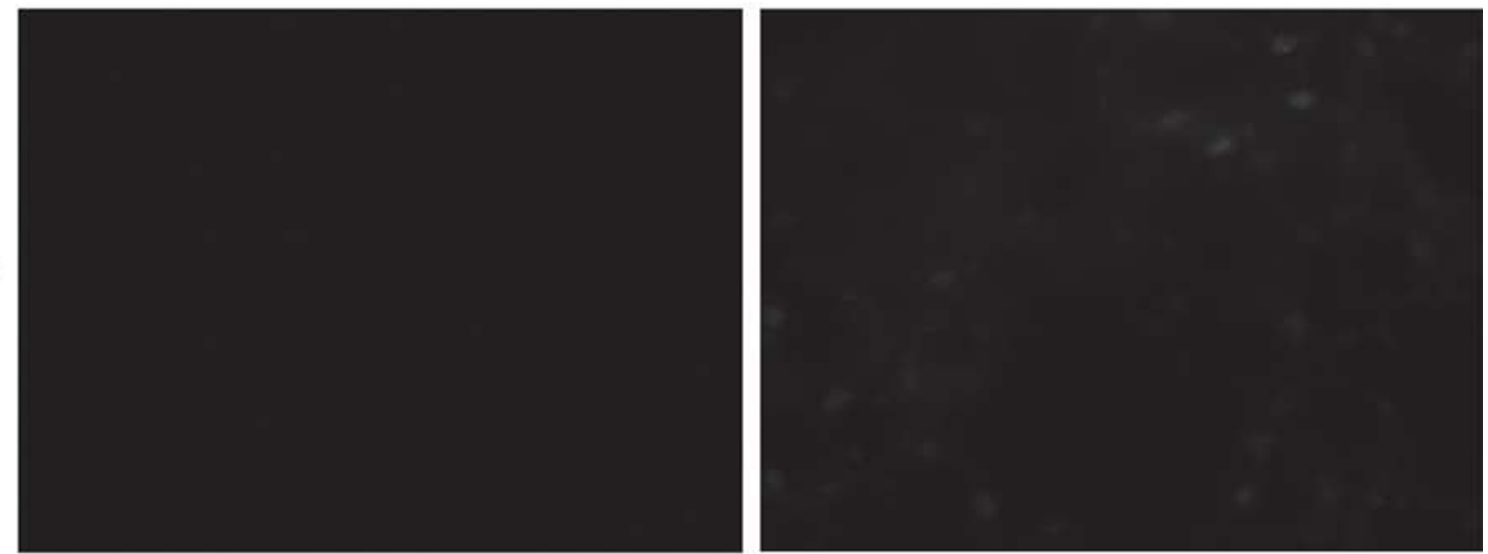

merge
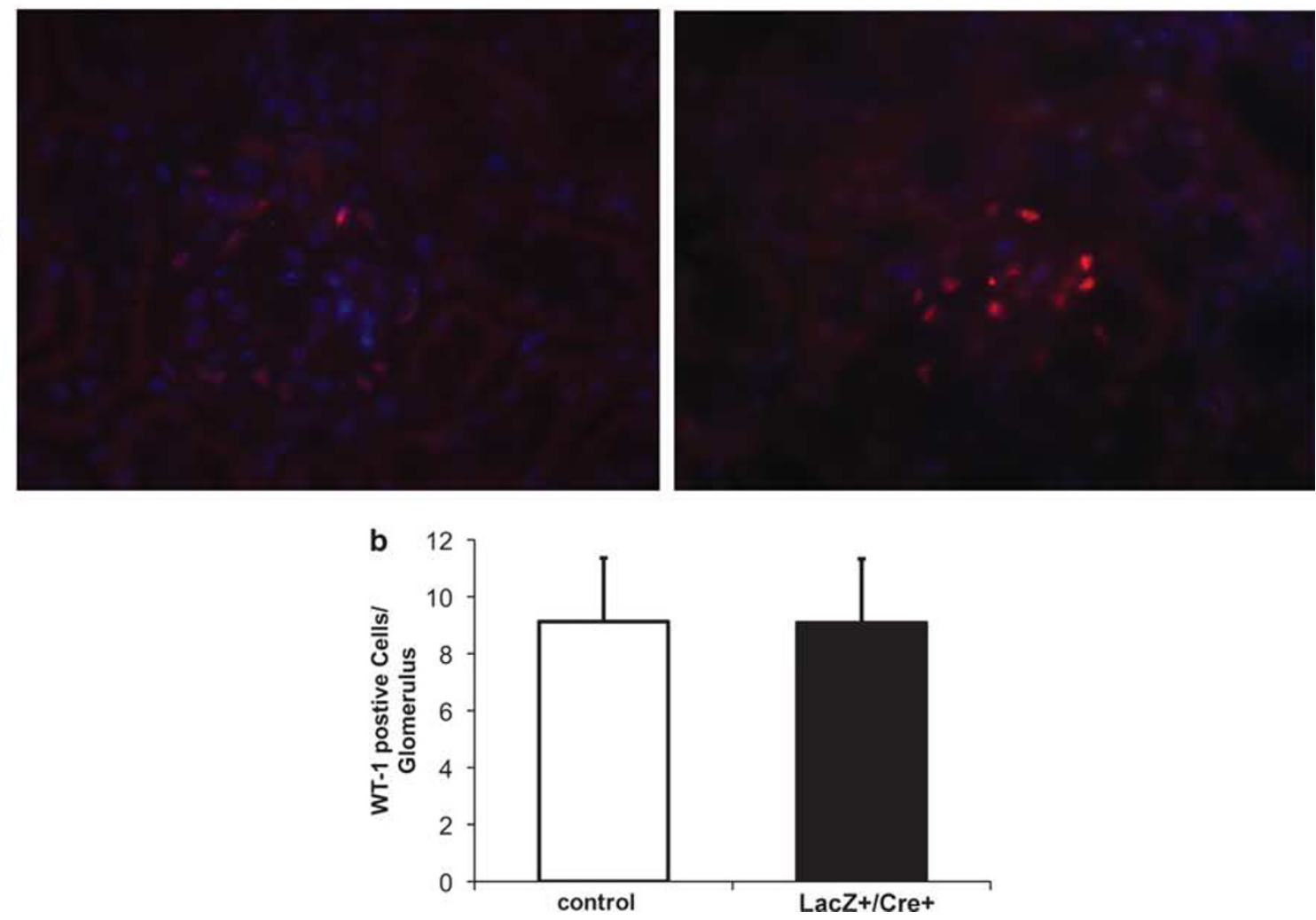
need to identify the specific GPCR or its ligand. Analogous to our studies, activated (QL) G $\alpha$ q was targeted to podocytes, ${ }^{37}$ and these mice developed proteinuria through a different mechanism. QL $\alpha \mathrm{q}$ mice had developmental defects, including smaller kidneys and reduced nephron number. There was downregulation of nephrin and other podocyte genes, although Col4a was not examined. QL $\alpha \mathrm{q}$ mice were more susceptible to puromycin aminonucleoside injury, and a subset of mice developed GS at 6 months of age, a finding that could occur from reduced nephron number. In contrast, QL $\alpha 12$ in podocytes did not affect renal development, nephron or podocyte number, and revealed altered regulation of collagen and GBM abnormalities.

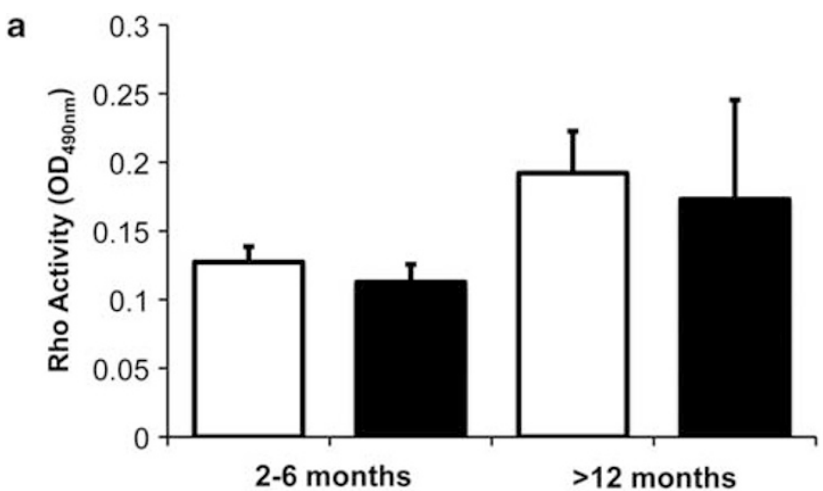

b
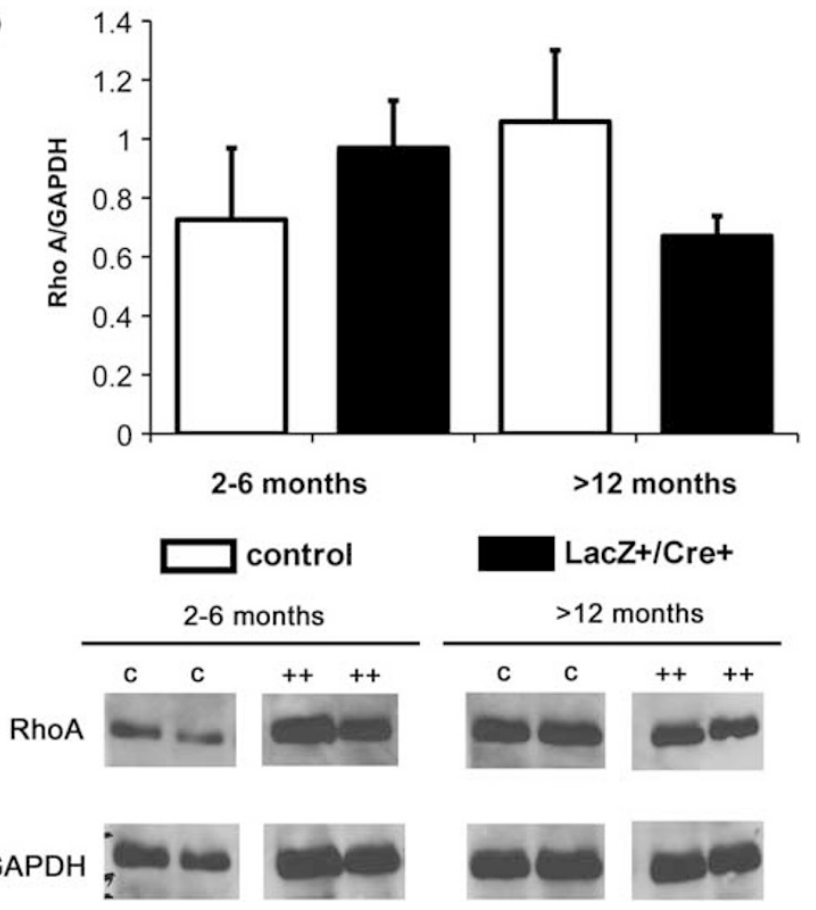

Figure 7 RhoA activity is not altered in $\mathrm{QL} \alpha 12^{\mathrm{Lacz}+/ \mathrm{Cre}+}$ mice. (a) Enzymelinked immunosorbent assay (ELISA) for activated RhoA was performed on young (2-6 months) and old ( $>12$ months) QL $\alpha 12^{\mathrm{LacZ}+/ \text { Cre }+}$ and control mice. (b) Total RhoA did not change in QL $\alpha 12^{\mathrm{LacZ}+/ \mathrm{Cre}+}$ mice as they age. Western blot analysis was performed to examine total RhoA. Blots were stripped and re-probed for glyceraldehyde 3-phosphate dehydrogenase (GAPDH) and ImageJ was used to determine RhoA/GAPDH expression.
Proteinuria developed in some $\mathrm{QL} \alpha 12^{\mathrm{LacZ}+/ \mathrm{Cre}+}$ mice by 4-6 months before morphological changes (Figures 3-5). By 12-14 months, there was some FP fusion that could account for the increase in proteinuria; however, the CMV promoter results in mosaic expression, and we estimate that only about half of podocytes express QL $\alpha 12$ (Figure 2). This focal expression is likely to account for the mild phenotype, but also recapitulates local differences in glomerular response to stress and the focal nature of GS. In fact, the majority of sclerotic glomeruli was located at the cortico-medullary junction, a region where the glomeruli are more susceptible to hemodynamic stress. ${ }^{38,39}$ Why some younger mice manifest proteinuria before morphological changes are detected is not clear. They do not show enhanced baseline Rho or Src activity, but they are more susceptible to LPS-induced proteinuria (without changes in Col4 gene expression (not shown)), suggesting that $\mathrm{QL} \alpha 12$ can promote functional effects on permeability. The absence of ultrastructural changes in young mice or after LPS suggests that perhaps through $\mathrm{G} \alpha 12$ localization in the major FPs, it regulates cortical actin and permeability. Although only about $5 \%$ of the glomeruli develop GS, proteinuria is likely to arise from a more global effect on significantly more glomeruli. This is based on the observation that $\mathrm{QL} \alpha 12$ is expressed in approximately $50 \%$ of glomeruli (Supplementary Figure 1) and $\mathrm{QL} \alpha 12$ expression increased proteinuria in LPS-treated mice without morphological or ultrastructural changes.

Mesangial expansion was prominent in the $\mathrm{QL} \alpha 12^{\mathrm{LacZ}+/ \mathrm{Cre}+}$ mice, and mesangial expansion is particularly characteristic of FSGS, membranous and diabetic nephropathy, Alport's syndrome and Denys-Drash syndrome. ${ }^{40}$ Mesangial expansion can contribute to proteinuria through a mechanism that does not require podocyte depletion (as seen in this study). ${ }^{41}$ In addition, both nephropathy and Alport's syndrome are both characterized by changes in collagen expression. ${ }^{42-44}$ Transcription of Col4a1 and A2 is co-regulated by the same promoter owing to head-to-head orientation in chromosome $13 \mathrm{q} 34 .{ }^{45}$ As a result, diseases affecting collagen IV expression will be associated with changes in both $\alpha 1$ (IV) and $\alpha 2($ IV)) as seen in both the above disease and QL $\alpha 12$ mice (Figure 8). However, Alport's syndrome is caused by mutations in $\alpha 3$, $\alpha 4$ or $\alpha 5$ (IV) collagen, leading to sustained $\alpha 1$ and $\alpha 2$ (IV) expression, whereas membranous nephropathy results from autoantibodies ${ }^{46}$ that promote podocyte injury and subepithelial deposits.

On the basis of the time course of proteinuria and morphological changes, we speculate that $\mathrm{G} \alpha 12$ modifies COL4 gene expression and the resulting basement membrane and endothelial abnormalities accrue with time. However, whether these changes reflect age-dependent effects or are the result of cumulative $G \alpha 12$ activation will require additional study. Since C57/B6 mice develop mild ultrastructural changes, cytokine activation and proteinuria with age (as seen in some control mice), the phenotypic differences seen in the older mice with $\mathrm{G} \alpha 12$ activation could represent 
a

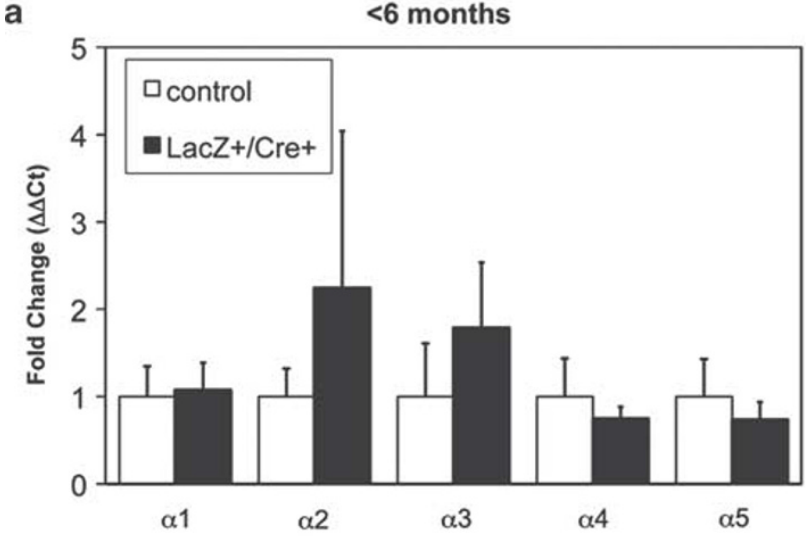

C

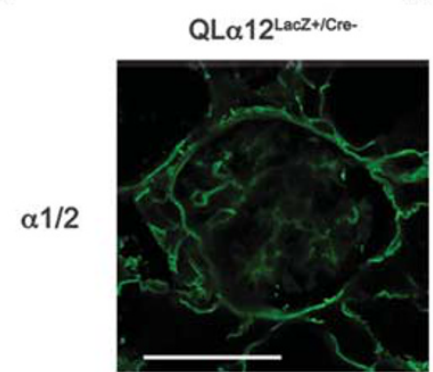

$<6$ mo

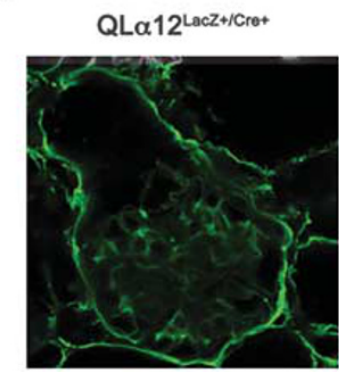

$\alpha 3$
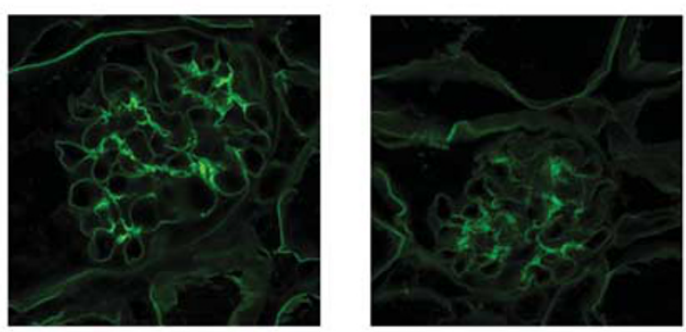

$\alpha 5$
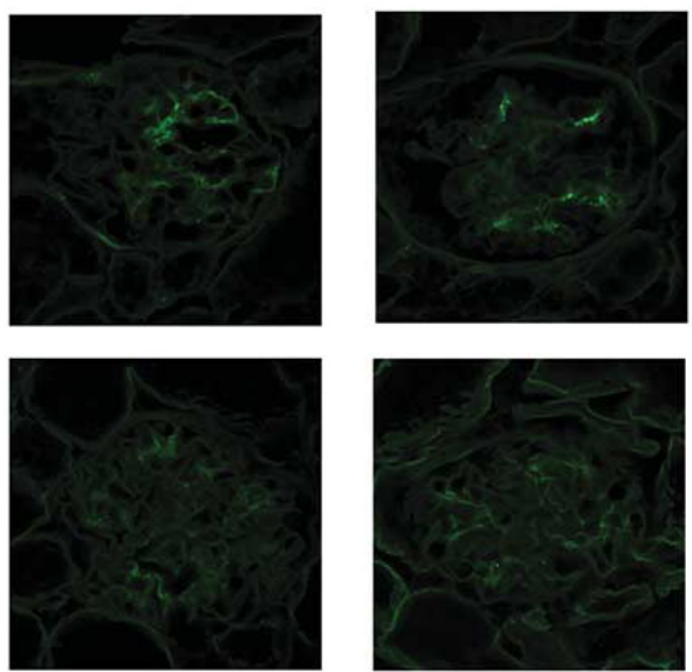

b

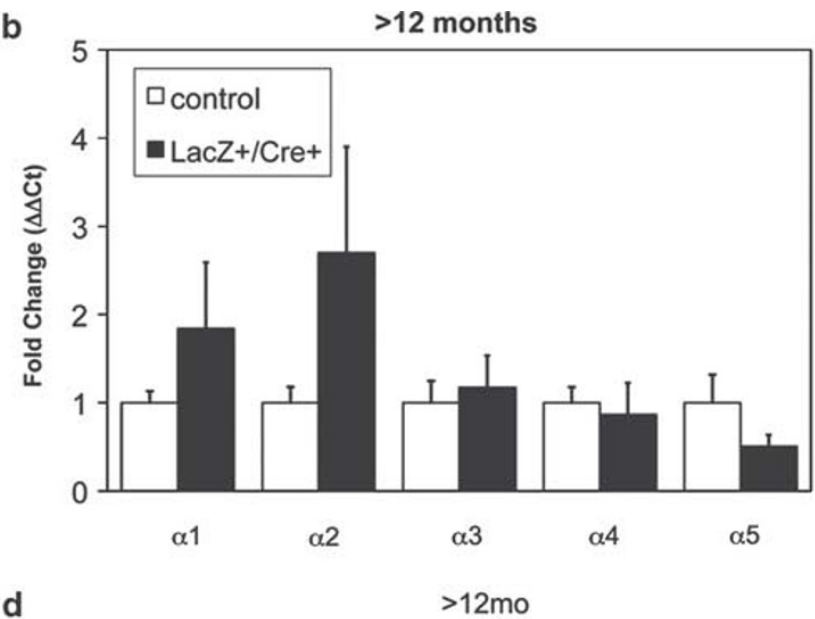

d

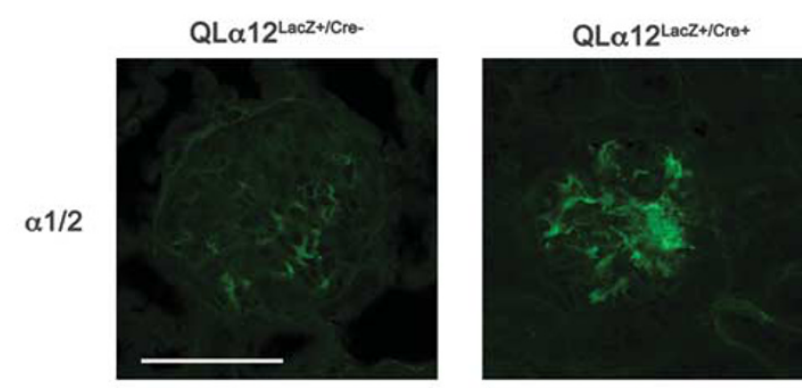

$\alpha 3$
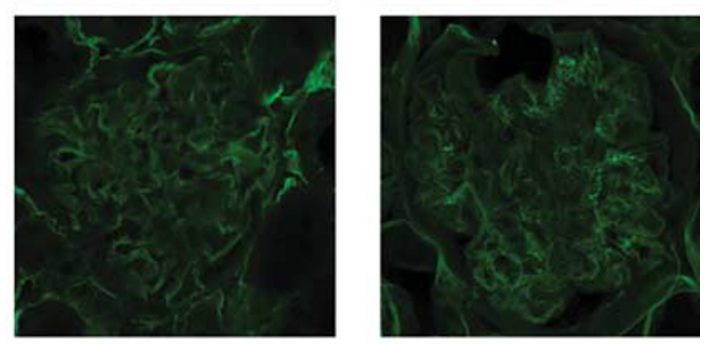

$\alpha 5$
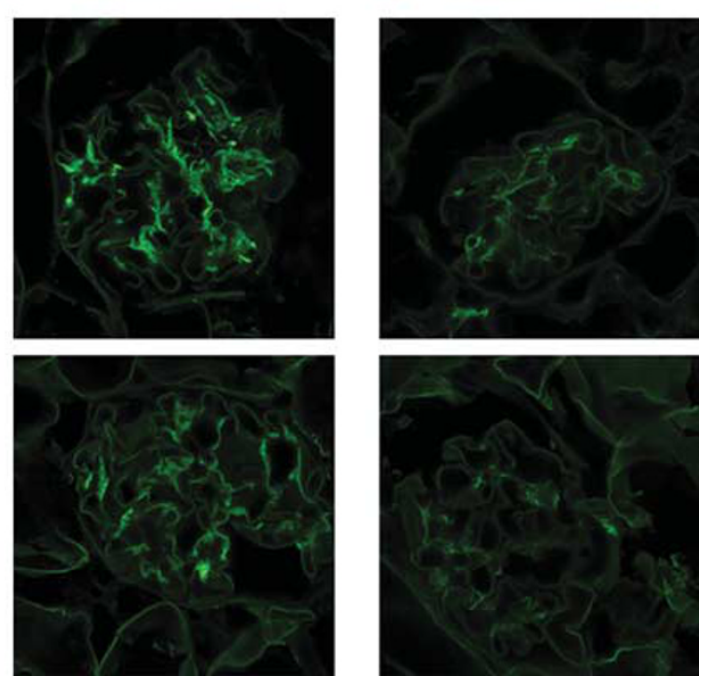

Figure 8 Collagen $(\alpha)$ IV is misregulated $\mathrm{QL} \alpha 12^{\mathrm{LacZ}+/ \mathrm{Cre}+}$ mice. $(\mathbf{a}, \mathbf{b})$ Col4a1, Col4a 2 and Col4a5 transcript expression are altered in $\mathrm{QL} \alpha 12^{\mathrm{LacZ}+/ \mathrm{Cre}+}$ mice $>12$ months of age. Various $\alpha$ chains of COL4 were examined in $\mathbf{a}(2-6$ month) or $\mathbf{b}$ ( $>12$ months) mice. Results were normalized to the 185 ribosomal subunit and graphed as relative expression compared with non-targeting control (normalized to 1); $n \geq 6$ mice for each experiment. (c, d) Immunofluorescent staining was performed on frozen kidney sections using collagen antibodies ( $\alpha 1 / 2$, Rockland; $\alpha 3$ NC1 (monoclonal antibody $(\mathrm{mAb}) 8 \mathrm{D} 1), \alpha 3 \alpha 4 \alpha 5 \mathrm{NC1}$ (mAb 26-20), $\alpha 5$ (polyclonal) $)^{52}$ and Alexa488 anti-mouse or anti-rabbit secondary antibody. Representative images are shown from QL $\alpha 12^{\mathrm{LacZ}+/ \mathrm{Cre}-}$ and QL $\alpha 12^{\mathrm{LacZ}+/ \mathrm{Cre}+}$ mice in c (2-6 month) or d (12-16 month). Scale bar $=100 \mu \mathrm{m}$. 
indirect effects on cumulative age-related changes in this mouse strain, or a cumulative time effect of $\mathrm{G} \alpha 12$ activation. Although the control mice do develop mild changes with age, the dramatic differences seen in the age- and sex-matched QL $\alpha 12$ mice strongly implicates the persistent G $\alpha 12$ activation as the etiology. Furthermore, the finding of upregulated COL4A1/2 seen with QL $\alpha 12$ expression in MDCK cells (Supplementary Figure 3) supports an important link between $\mathrm{G} \alpha 12$ activation and Col4A1/2 gene expression.

Although $\mathrm{G} \alpha 12$ stimulates TGF $\beta^{20,21}$ and could promote GS, we were unable to detect increased TGF $\beta$ in either young or old mice (not shown). However, an alternative mechanism is suggested by the increased number of subepithelial GBM membrane projections (Figure 5) similar to findings seen in DDR1 and integrin $\alpha 2$ knockout mice. ${ }^{47,48}$ DDR1 is a tyrosine kinase receptor for collagen IV, and we previously showed that $G \alpha 12$ regulates $\alpha 2 \beta 1$ integrin signaling and attachment, ${ }^{17}$ thus suggesting that persistent $\mathrm{G} \alpha 12$ activation might lead to podocyte changes in integrin signaling. The onset of proteinuria is during adulthood and virtually all mice have proteinuria by mid-life (12-16 months, normal C57/B6 mouse lifespan $\sim 3$ years $^{49}$ ). With aging, podocytes may accumulate damage from a variety of sources, including GPCR-linked inflammatory and vasoactive mediators. ROS, inflammation and vascular changes occur in hypertensive and diabetic kidney disease, and ROS directly activates $\mathrm{G} \alpha$ subunits. ${ }^{50}$ On the basis of these observations, we suggest that this model of slowly progressive kidney disease will be valuable for understanding CKD progression in humans. Consistent with GPCR pathways regulating age-related kidney damage, $\mathrm{AT}_{1}$ receptor knockout mice exhibit decreased oxidative damage and outlive their wildtype littermates. ${ }^{51}$ The glomerular filtration rate declines with age, but it is unclear whether this is part of normal aging or represents injury from cumulative exposures. If decreased renal function and GS occur through repetitive activation of podocyte signaling pathways, it is tempting to speculate that inhibiting $\mathrm{G} \alpha 12$ pathways in podocytes may provide new treatments to protect renal function and delay CKD progression.

\section{ACKNOWLEDGEMENTS}

We thank Dr Dorin-Bogdan Borza for his consultation and the gift of the collagen antibodies; Drs Johannes Schlondorff and Michael Ross for their knowledge of podocytes and glomerular isolation; and Andrea Bernhardy for her technical assistance. In addition, we thank Dr Dennis Brown and Margaret McLaughlin for help with the immunoelectron microscopy, and Dr Hui Chen and Colleen Ford for their technical assistance with EM of the transgenic mice. This research was supported by NIH Grants R21DK065932 and R01GM055223 to BMD. IB was supported by NIH training Grant T32DK007527. IB conceived and carried out experiments, analyzed data, prepared figures and contributed to writing and editing the paper; WY, $\mathrm{SB}, \mathrm{HN}$ and MT conceived and carried out experiments and analyzed data; MP contributed to editing the paper; JH carried out experiments, analyzed data, prepared figures and contributed to editing the paper; and BMD conceived of experiment and contributed to writing and editing the paper.
Supplementary Information accompanies the paper on the Laboratory Investigation website (http://www.laboratoryinvestigation.org)

\section{DISCLOSURE/CONFLICT OF INTEREST}

The authors declare no conflict of interest.

1. US Renal Data System, USRDS 2010 Annual Data Report: Atlas of Chronic Kidney Disease and End-Stage Renal Disease in the United States; National Institutes of Health, National Institute of Diabetes and Digestive and Kidney Diseases, Bethesda, MD, 2010; http://www.usrds.org/faq.aspx.

2. Zhou XJ, Rakheja D, Yu X, et al. The aging kidney. Kidney Int 2008;74: 710-720.

3. Schmitt R, Cantley LG. The impact of aging on kidney repair. Am J Physiol Renal Physiol 2008;294:F1265-F1F72.

4. Wharram BL, Goyal M, Wiggins JE, et al. Podocyte depletion causes glomerulosclerosis: diphtheria toxin-induced podocyte depletion in rats expressing human diphtheria toxin receptor transgene. J Am Soc Nephrol 2005;16:2941-2952.

5. Matsusaka T, Xin J, Niwa S, et al. Genetic engineering of glomerular sclerosis in the mouse via control of onset and severity of podocytespecific injury. J Am Soc Nephrol 2005;16:1013-1023.

6. Worzfeld T, Wettschureck N, Offermanns S. G12/G13-mediated signalling in mammalian physiology and disease. Trends Pharmacol Sci 2008;29:582.

7. Riobo NA, Manning DR. Receptors coupled to heterotrimeric G proteins of the G12 family. Trends Pharmacol Sci 2005;26:146-154.

8. Buhl AM, Johnson NL, Dhanasekaran N, et al. $\mathrm{G} \alpha 12$ and $\mathrm{G} \alpha 13$ stimulate Rho-dependent stress fiber formation and focal adhesion assembly. J Biol Chem 1995;270:24631-24634.

9. Jiang $\mathrm{H}, \mathrm{Wu} \mathrm{D}$, Simon Ml. The transforming activity of activated G $\alpha 12$. FEBS Lett 1993;330:319-322.

10. Meyer TN, Hunt J, Schwesinger $C$, et al. $G \alpha 12$ regulates epithelial cell junctions through Src tyrosine kinases. Am J Physiol Cell Physiol 2003; 285:C1281-C1293.

11. Sabath $E$, Negoro $H$, Beaudry $S$, et al. $G \alpha 12$ regulates protein interactions within the MDCK cell tight junction and inhibits tightjunction assembly. J Cell Sci 2008;121:814-824.

12. Meyer TN, Schwesinger C, Denker BM. Zonula occludens-1 is a scaffolding protein for signaling molecules: $G \alpha 12$ directly binds to the Src homology 3 domain and regulates paracellular permeability in epithelial cells. J Biol Chem 2002;277:24855-24858.

13. Meigs $T E$, Fields $T A$, McKee DD, et al. Interaction of $G \alpha 12$ and $G \alpha 13$ with the cytoplasmic domain of cadherin provides a mechanism for $\beta$-catenin release. Proc Natl Acad Sci USA 2001;98:519-524.

14. Meigs TE, Fedor-Chaiken M, Kaplan DD, et al. Ga12 and Ga13 negatively regulate the adhesive functions of cadherin. J Biol Chem 2002;277:24594-24600.

15. Goulimari $P$, Kitzing TM, Knieling $H$, et al. $G \alpha 12 / 13$ is essential for directed cell migration and localized Rho-Dia1 function. J Biol Chem 2005;280:42242-42251.

16. Yanamadala V, Negoro H, Gunaratnam L, et al. $G \alpha 12$ stimulates apoptosis in epithelial cells through JNK1-mediated Bcl-2 degradation and up-regulation of IKBa. J Biol Chem 2007;282:24352-24363.

17. Kong $T, X u D, Y u W$, et al. $G \alpha 12$ inhibits $\alpha 2 \beta 1$ integrin-mediated Madin-Darby canine kidney cell attachment and migration on collagen-i and blocks tubulogenesis. Mol Biol Cell 2009;20:4596-4610.

18. Togawa A, Miyoshi J, Ishizaki $\mathrm{H}$, et al. Progressive impairment of kidneys and reproductive organs in mice lacking Rho GDl $\alpha$. Oncogene 1999;18:5373-5380.

19. Pollak MR. Focal segmental glomerulosclerosis: recent advances. Curr Opin Nephrol Hypertens 2008;17:138-142.

20. Tsunoda $\mathrm{S}$, Yamabe $\mathrm{H}$, Osawa $\mathrm{H}$, et al. Cultured rat glomerular epithelial cells show gene expression and production of transforming growth factor- $\beta$ : expression is enhanced by thrombin. Nephrol Dial Transplant 2001;16:1776-1782.

21. Lee SJ, Yang JW, Cho IJ, et al. The gep oncogenes, G $\alpha 12$ and $\mathrm{G} \alpha 13$, upregulate the transforming growth factor- $\beta 1$ gene. Oncogene 2009;28:1230.

22. Martini S, Eichinger F, Nair V, et al. Defining human diabetic nephropathy on the molecular level: Integration of transcriptomic profiles with biological knowledge. Rev Endocr Metab Disord 2008;9:267-274. 
23. Rhodes DR, Kalyana-Sundaram S, Mahavisno V, et al. Oncomine 3.0: genes, pathways, and networks in a collection of 18000 cancer gene expression profiles. Neoplasia 2007;9:166-180.

24. Moeller MJ, Soofi A, Sanden S, et al. An efficient system for tissuespecific overexpression of transgenes in podocytes in vivo. Am J Physiol Renal Physiol 2005;289:F481-F488.

25. Takemoto M, Asker N, Gerhardt H, et al. A new method for large scale isolation of kidney glomeruli from mice. Am J Pathol 2002;161:799-805.

26. Zheng $S, Y u P$, Zeng $C$, et al. G $\alpha 12$ - and $G \alpha 13$-protein subunit linkage of D5 dopamine receptors in the nephron. Hypertension 2003;41: 604-610.

27. Miyamoto M, Yoshida $\mathrm{Y}$, Taguchi I, et al. In-depth proteomic profiling of the normal human kidney glomerulus using two-dimensiona protein prefractionation in combination with liquid chromatographytandem mass spectrometry. J Proteome Res 2007;6:3680-3690.

28. Moeller MJ, Sanden SK, Soofi A, et al. Podocyte-specific expression of cre recombinase in transgenic mice. Genesis 2003;35:39-42.

29. Moeller MJ, Sanden SK, Soofi A, et al. Two gene fragments that direct podocyte-specific expression in transgenic mice. J Am Soc Nephrol 2002;13:1561-1567.

30. Yamaguchi $\mathrm{Y}$, Katoh $\mathrm{H}$, Mori $\mathrm{K}$, et al. Ga12 and Ga13 interact with Ser/Thr protein phosphatase type 5 and stimulate its phosphatase activity. Curr Biol 2002;12:1353.

31. Mundel P, Shankland SJ. Podocyte biology and response to injury. J Am Soc Nephrol 2002;13:3005-3015.

32. Reiser J, von Gersdorff G, Loos M, et al. Induction of B7-1 in podocytes is associated with nephrotic syndrome. J Clin Invest 2004;113: 1390-1397.

33. Mundlos S, Pelletier J, Darveau A, et al. Nuclear localization of the protein encoded by the Wilms' tumor gene WT1 in embryonic and adult tissues. Development 1993;119:1329-1341.

34. Ma YC, Huang J, Ali S, et al. Src tyrosine kinase is a novel direct effector of $\mathrm{G}$ proteins. Cell 2000;102:635-646.

35. Pavenstädt H, Kriz W, Kretzler M. Cell biology of the glomerular podocyte. Physiol Rev 2003;83:253-307.

36. White MA, Nicolette $C$, Minden A, et al. Multiple ras functions can contribute to mammalian cell transformation. Cell 1995;80:533-541.

37. Wang L, Fields TA, Pazmino K, et al. Activation of G $\alpha q$-coupled signaling pathways in glomerular podocytes promotes renal injury. J Am Soc Nephrol 2005;16:3611-3622.

38. Olson J. Renal disease caused by hypertension (Chapter 21). In: Jennette J, Olson J, Schwartz M, Silva F (eds) Heptinstall's Pathology of the Kidney, 6th edn. Lippincott Williams \& Wilkins: Philadelphia, 2007, pp 937-990.

39. Brezis $M$, Rosen $S$, Silva $P$, et al. Renal ischemia: a new perspective. Kidney Int 1984;26:375-383.

40. Lee HS. Pathogenic role of TGF-beta in the progression of podocyte diseases. Histol Histopathol 2011;26:107-116.

41. Wiggins JE, Goyal M, Sanden SK, et al. Podocyte hypertrophy, 'adaptation,' and 'decompensation' associated with glomerular enlargement and glomerulosclerosis in the aging rat: prevention by calorie restriction. J Am Soc Nephrol 2005;16:2953-2966.

42. Zhang YZ, Lee HS. Quantitative changes in the glomerular basement membrane components in human membranous nephropathy. J Pathol 1997;183:8-15

43. Kalluri R, Shield CF, Todd P, et al. Isoform switching of type IV collagen is developmentally arrested in X-linked Alport syndrome leading to increased susceptibility of renal basement membranes to endoproteolysis. J Clin Invest 1997;99:2470-2478.

44. Kim TS, Kim JY, Hong $\mathrm{HK}$, et al. mRNA expression of glomerular basement membrane proteins and TGF- $\beta 1$ in human membranous nephropathy. J Pathol 1999;189:425-430.

45. Sado Y, Kagawa M, Naito I, et al. Organization and expression of basement membrane collagen IV genes and their roles in human disorders. J Biochem 1998;123:767-776.

46. Beck LH, Bonegio RGB, Lambeau G, et al. M-type phospholipase A2 receptor as target antigen in idiopathic membranous nephropathy. $\mathrm{N}$ Engl J Med 2009;361:11-21.

47. Gross O, Beirowski B, Harvey SJ, et al. DDR1-deficient mice show localized subepithelial GBM thickening with focal loss of slit diaphragms and proteinuria. Kidney Int 2004;66:102-111.

48. Girgert R, Martin M, Kruegel J, et al. Integrin $\alpha 2$-deficient mice provide insights into specific functions of collagen receptors in the kidney. Fibrogen Tissue Repair 2010;3:19.

49. Harrison D. Baseline life span data: commonly used JAX Mice and crosses. Available from http://research.jax.org/faculty/harrison/ger1vi_ LifeStudy1.html(cited 30 March 2011).

50. Nishida M, Maruyama Y, Tanaka R, et al. $\mathrm{G} \alpha(\mathrm{i})$ and $\mathrm{G} \alpha(\mathrm{o})$ are target proteins of reactive oxygen species. Nature 2000;408:492-495.

51. Benigni A, Corna D, Zoja C, et al. Disruption of the Ang II type 1 receptor promotes longevity in mice. J Clin Invest 2009;119:524-530.

52. Kang JS, Wang X-P, Miner JH, et al. Loss of $\alpha 3 / \alpha 4$ (IV) collagen from the glomerular basement membrane induces a strain-dependent isoform switch to $\alpha 5 \alpha 6$ (IV) collagen associated with longer renal survival in Col4a3-/- Alport mice. J Am Soc Nephrol 2006;17:1962-1969. 